\title{
Unprecedented J-Aggregated Dyes in Pure Organic Solvents
}

Hegoi Manzano, , Ixone Esnal, ${ }^{\text {a }}$ Tamara Marques-Matesanz, ${ }^{\mathrm{b}}$ Jorge Bañuelos, ${ }^{\mathrm{a}}$ Iñigo LópezArbeloa, ${ }^{\mathrm{a}}$ María J. Ortiz, ${ }^{\mathrm{c}}$ Luis Cerdán, ${ }^{* \mathrm{~d}}$ Angel Costela, ${ }^{\mathrm{d}}$ Inmaculada García-Moreno, ${ }^{\mathrm{d}}$ and Jose Luis Chiara*b

aa Departamento de Química Física Universidad del País Vasco-EHU Facultad de Ciencias y Tecnología, Apartado 644, 48080-Bilbao, Spain

Instituto de Química Orgánica General, IQOG-CSIC, Juan de la Cierva 3, 28006 Madrid, Spain. E-mail: jl.chiara@csic.es

${ }^{\mathrm{c}}$ Departamento de Química Orgánica I, Facultad de Ciencias Químicas, Universidad Complutense de Madrid, Ciudad Universitaria s/n, 28040 Madrid, Spain

dInstituto Química-Física “Rocasolano”, IQFR-CSIC, Serrano 119, 28006 Madrid, Spain. E-mail: 1cerdan@iqfr.csic.es

Keywords: fluorescent dyes, J-aggregates, BODIPY dyes, lasers, atomistic simulations

Abstract. We describe the design and synthesis of the first organic dyes enabling spontaneous formation of stable J-aggregates in common organic solvents without additives. The new dyes are $O$-BODIPYs with a $B$-spiranic 4,4-diacyloxyl substitution pattern. Key to the effectiveness of the J-aggregation process is the high conformational rigidity of the $B$ spiranic molecular design as well as the orthogonal disposition of the $B$-diacyloxyl substituent and the meso-aryl group with respect to the mean plane of the borodiazaindacene. Atomistic simulations, both in vacuum and in a solvent cage, support the dynamics of the J-aggregation process as well as its dependence on the alkylation 
pattern of the BODIPY chromophore. A detailed analysis of the photophysical and laser properties of the new dyes provides convincing evidence for the unambiguous assignment of these J-aggregates and their dependence on the environmental conditions.

\section{INTRODUCTION}

J-aggregated organic dyes, due to their intriguing optical properties, have played an important role in the development of active smart molecules for advanced applications in biomolecular science, nanophotonics and molecular plasmonic. ${ }^{[1]}$ To date, J-aggregation of organic dyes has been extensively studied on cyanine, porphyrin, and perylene bisimide structures, ${ }^{[1]}$ and, more recently but to a lesser extent, on functionalized BODIPYs. ${ }^{[2]} \mathrm{J}-$ aggregates are ubiquitously formed in various environments (basic and acid solvents, colloidal suspensions, embedded in micellar media, occluded in vesicles and mesoporous materials $)^{[3]}$ and in polar solvents such as water in the presence of high concentrations of salts. ${ }^{[4]}$ However, although dye assemblies with J-type coupling have attracted extensive interest, they have never been observed in the simplest system, such as an organic dye dissolved in a pure organic solvent, which is a highly desired and long-sought-after effect, since it would overcome some drawbacks imposed by the molecular structure and/or the solvent properties in the self-assembly molecular processes.

Among organic dyes, 4,4-difluoro-4-bora-3a,4a-diaza-s-indacenes ( $F$-BODIPYs) are

considered today as one of the most useful and versatile fluorophores. ${ }^{[5]}$ The interest in BODIPY dyes originates from their outstanding photophysical properties, such as high absorption coefficient, high fluorescence quantum yield, high photostability, and low sensitivity to medium effects. Currently, the development of new fluorescent BODIPYs has 
become a booming area of research due to their potential applications as sensors in biology and in clinical diagnosis, ${ }^{[6]}$ photosensitizers for photodynamic therapy (PDT) ${ }^{[7]}$ laser generators,${ }^{[8]}$ manufacture of light emitting diodes (OLED),${ }^{[9]}$ photovoltaic cells, ${ }^{[10]}$ and electroluminescent devices, ${ }^{[9]}$ in addition to the usual conventional applications of organic dyes. These and other emerging applications are conditioned by the emission wavelength, quantum yield and stability of the dyes under the working conditions needed for each specific use, which can be particularly demanding as it is the case with the new imaging techniques developed in optical microscopy that require high laser intensity irradiation. Chemical modification of the carbon skeleton is the usual approach to modulate the absorption- and fluorescence-spectroscopic properties of the chromophore. In comparison, modification at the boron center of $F$-BODIPYs, via substitution of $\mathrm{F}$ by $\mathrm{C}$ - and (to date) O-nucleophiles, generally has a minor effect on these properties, but can substantially affect fluorescent quantum yields, ${ }^{[11]}$ laser efficiencies ${ }^{[1 \mathrm{~b}]}$ chemical $^{[12]}$ and photochemical ${ }^{[11 \mathrm{~b}, 12 \mathrm{~b}]}$ stabilities, oxidation and reduction potentials, ${ }^{[13]}$ solubilities, ${ }^{[12 b, 13 a, 14]}$ and aggregation properties. ${ }^{[15]}$ In addition, functionalization at boron also provides a simple and versatile access to BODIPY diads (and higher combinations), ${ }^{[16]}$ cassettes, ${ }^{[17]}$ and chiral BODIPYs ${ }^{[18]}$ with interesting chirooptical properties.

\section{Figure 1. Retrosynthesis of the new $B$-spiranic 4,4-diacyloxyl BODIPYs}

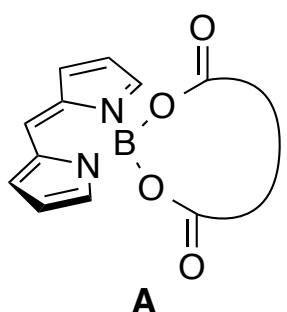

A

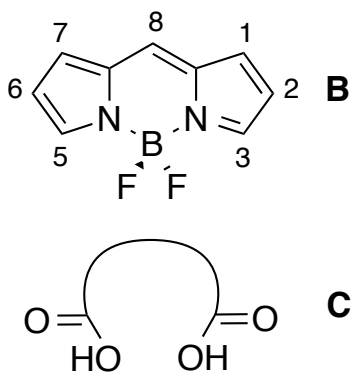


We describe herein the synthesis of a new type of $O$-BODIPYs (A) with a spiranic $B$-diacyloxy rigid structure by reaction of $F$-BODIPYs (B) with dicarboxylic acids (C) (Figure 1). The conformational rigidity introduced by this molecular design boost fluorescence quantum yield, photochemical stability, and laser efficiency of the new dyes, while the anticipated orthogonal disposition of the chelated diacyloxyl substituent with respect to the plane of the boradiazaindacene framework hinders intermolecular $\pi$-stacking of the chromophores thus avoiding formation of H-dimers in solution that strongly quench fluorescence. The new $O$-diacyl-BODIPYs here reported are the first organic dyes that enable to achieve spontaneous and stable J-aggregation in pure organic solvents allowing the excitation of efficient and tunable laser emission of both the monomeric and $\mathrm{J}$ aggregated forms. A detailed analysis of the photophysical and laser properties of the new dyes together with X-ray crystallography studies and atomistic simulations, both in vacuum and in a solvent cage, provide convincing evidence for the unambiguous assignment of these J-aggregates and their dependence on the environmental conditions. In this way, the rational design of the new $O$-diacyl-BODIPYs offers the possibility of tuning their properties allowing deeper insights into the underlying factors that control and enhance the effectiveness and extension of the J-aggregation process. Furthermore, the present work overcomes some of the most important limitations to efficiently induce spontaneous Jaggregation of organic dyes in organic solvents and outperforms closely related results reported by other groups in this direction. On the one hand, F. Wurther et al. ${ }^{[\mathrm{a}]}$ described fluorescent J-aggregates of core-substituted perylene bisimides (PBIs) in organic solvent like methylcyclohexane, but in this case J-aggregation was driven by intermolecular hydrogen bonding of appropriately functionalized monomeric PBI units resulting in the 
formation of supramolecular polymeric chains of densely packed and strongly excitonically coupled PBI chromophores. For this reason, the J-aggregation processes of these PBI units could only be achieved in non-protic/non-polar solvents, where hydrogen bonds are particularly strong. On the other hand, Choi et $a l^{[2 b]}$ described the first structurally characterized genuine J-aggregates in a BODIPY dye, but in this case J-aggregation required the addition of a large amount $(90 \% \mathrm{v} / \mathrm{v})$ of a non-solvent (water) to a solution of the dye in an organic solvent (acetonitrile), which triggered the formation of colloidal aggregates.

\section{RESULTS AND DISCUSSION}

Synthesis of spiranic B-diacyloxy BODIPYs. Previously described procedures for the synthesis of $O$-BODIPYs from the corresponding $F$-BODIPYs have relied on the direct nucleophilic displacement of fluorine atoms on boron by metal alcoxides ${ }^{11,, 12 a, 13 a, 34 a}$ or trimethylsilyl esters, ${ }^{12 \mathrm{~b}}$ and on two-step processes via preactivation of the boron center with $\mathrm{BCl}_{3},{ }^{[19 \mathrm{~b}-\mathrm{d}]} \mathrm{BBr}_{3},{ }^{[19 \mathrm{c}, 20]} \mathrm{AlCl}_{3},{ }^{[11 \mathrm{~b}, 21]}$ or TMSOTf. ${ }^{[11 \mathrm{c}, 14 \mathrm{c}, 22]}$ Acid- and photochemicallypromoted interexchange of O-substituents on boron have been also successfully employed to prepare new $O$-BODIPYs from known ones. ${ }^{[12 \mathrm{a}, 23]}$ We selected readily available $F$ BODIPY $\mathbf{1}^{[24]}$ and malonic acid (a) (Figure 2) for an initial screening of reaction conditions leading to the corresponding $B$-spiranic 4,4-diacyloxy-BODIPY. A recent report ${ }^{[12 \mathrm{a}]}$ on the efficient and clean transformation of a 4,4-dimethoxy-BODIPY into the corresponding 4,4diacyloxy-BODIPY by reaction with dichloroacetic acid (in $\mathrm{CH}_{2} \mathrm{Cl}_{2}$ at room temperature) led us to try this route first. To this end, we prepared the required 4,4-dimethoxy-BODIPY 5 in moderate yield by a modification of a known procedure ${ }^{[13 a]}$ (Scheme 1). However, treatment of $\mathbf{5}$ with a stoichiometric amount of malonic acid under different conditions 
Figure 2. Starting F-BODIPYs, dicarboxylic acids, hydroxyacids and monocarboxylic acids

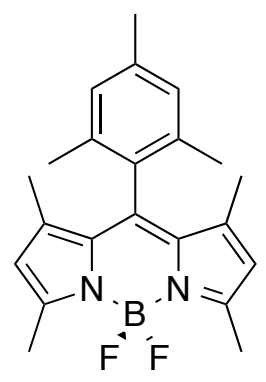

1<smiles>C=c1c(CC)c(C)n(BPF)c1=C(c1ccc(Br)cc1)c1c(C)c(CC)c(C)n1PC</smiles>

3<smiles>O=C(O)CC(=O)O</smiles>

a<smiles>O=C(O)C1(C(=O)O)CCCC1</smiles>

d<smiles>O=C(O)C(=O)O</smiles>

g<smiles>O=C(O)C1(C(=O)O)CC1</smiles>

b<smiles>O=C(O)C1(C(=O)O)CCCCC1</smiles>

e<smiles>O=C(O)c1ccccc1O</smiles>

h<smiles>Cc1cc(C)c(C2=C(c3cccn3B(F)F)n3cccc32)c(C)c1</smiles>

2<smiles></smiles>

4<smiles>O=C(O)C1(C(=O)O)CCC1</smiles>

c<smiles>CC(C)(C(=O)O)C(=O)O</smiles>
f<smiles>O=C(O)CCl</smiles>

i

(THF, room temperature, $48 \mathrm{~h}$; or $100{ }^{\circ} \mathrm{C}$ under microwave irradiation, $1 \mathrm{~h}$ ) led mostly to unreacted 5 together with a mixture of uncharacterized minor products. After further experimentation, we finally found that the reaction of $\mathbf{1}$ with a stoichiometric amount of 


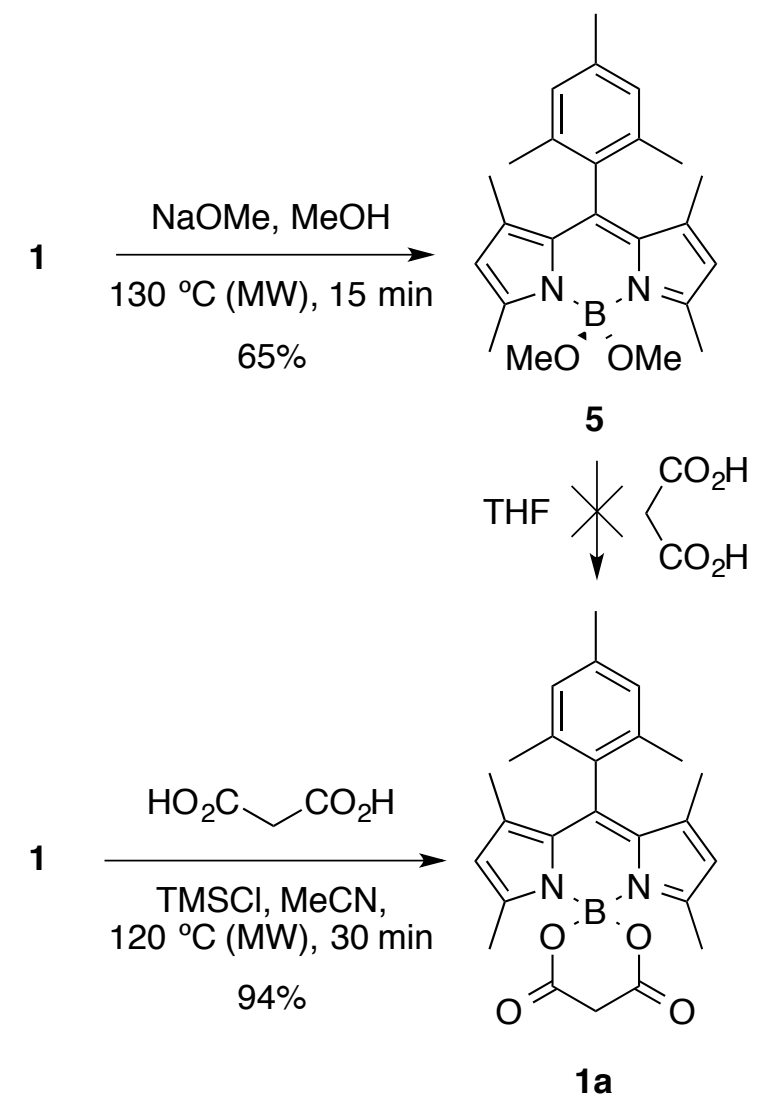

malonic acid (1.1 equivalents) in the presence of excess TMSCl (10-20 equivalents) in anhydrous $\mathrm{MeCN}$ under microwave heating $\left(120^{\circ} \mathrm{C}, 30 \mathrm{~min}\right)$ optimally afforded the targeted 4,4-diacyloxy-BODIPY 1a in excellent yield (94\%) after chromatographic purification (Scheme 1). Although we have not carried out any mechanistic investigation on this transformation, the rapid color change from orange to dark red observed upon addition of TMSCl to the solution of the starting F-BODIPY may indicate that a $\mathrm{F}$ to $\mathrm{Cl}$ exchange on boron is taking place first, ${ }^{[19]}$ facilitating the subsequent exchange with the carboxylate groups. 
Figure 3. Structures and isolated yields of the new $O$-BODIPYs

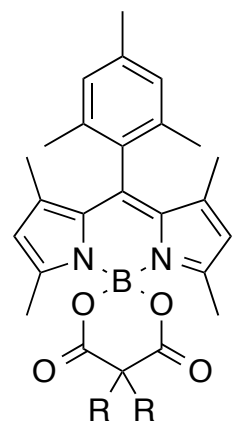

1b, $\mathrm{R}, \mathrm{R}=\left(\mathrm{CH}_{2}\right)_{2}(85 \%)$

1c, $R, R=\left(\mathrm{CH}_{2}\right)_{3}(98 \%)$

1d, $\mathrm{R}, \mathrm{R}=\left(\mathrm{CH}_{2}\right)_{4}(74 \%)$

1e, $\mathrm{R}, \mathrm{R}=\left(\mathrm{CH}_{2}\right)_{5}(0 \%)$

1f, $\mathrm{R}=\mathrm{Me}(0 \%)$

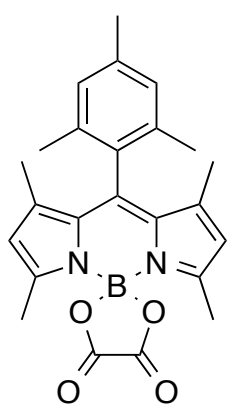

1 g (97\%)

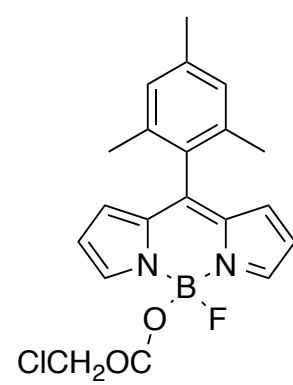

2i (12\%)

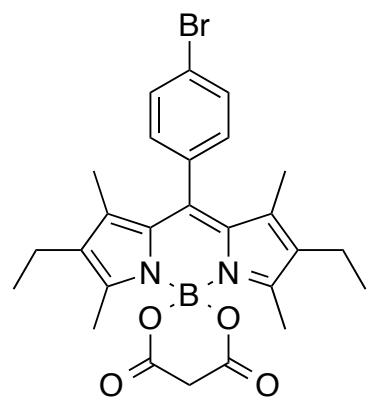

3a $(68 \%)$

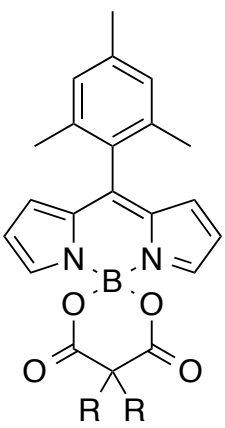

2b, $R, R=\left(\mathrm{CH}_{2}\right)_{2}(89 \%)$

2e, $R, R=\left(\mathrm{CH}_{2}\right)_{5}(60 \%)$

2f, $R=\operatorname{Me~}(0 \%)$

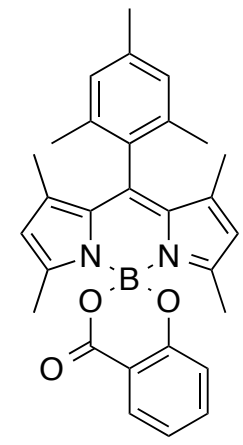

1h $(87 \%)$
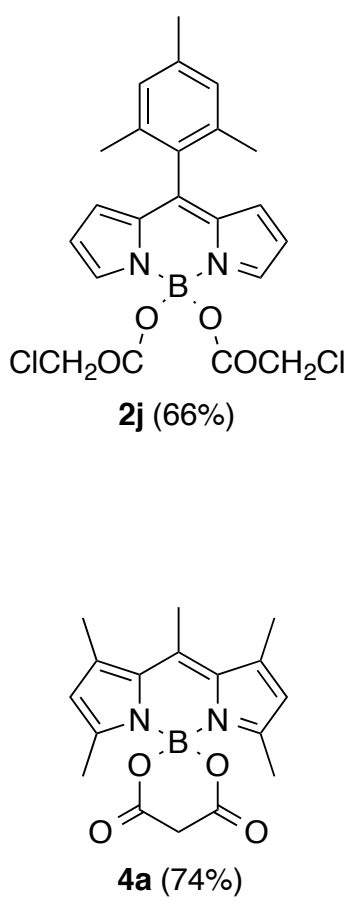
Using this optimized and simple method, we readily prepared a series of new 4,4diacyloxy-BODIPYs by reaction of $F$-BODIPYs $\mathbf{1 - 4} \mathbf{4}^{[1 \mathrm{a}, 25]}$ with malonic acid and several 2,2-disubstituted malonic acid derivatives a-e (Figures 2 and 3). Evaporation of the solvent generally afforded a very clean reaction crude (as observed by TLC and ${ }^{1} \mathrm{H}$ NMR analysis), with practically $100 \%$ conversion of the starting F-BODIPY, from which the 4,4diacyloxy-BODIPY could be readily isolated by short column chromatography in smallscale reactions $(<100 \mathrm{mg})$. For larger scale syntheses, simple recrystallization of the crude product could be a more practical and convenient purification procedure given the high crystallinity generally observed for these 4,4-diacyloxy-BODIPYs. We found that the reaction failed in those cases where a serious steric interaction would occur between the substituents at positions C-3 and -5 of the BODIPY framework and at the central carbon of the malonyl group, which share the same molecular plane in the expected product. Thus, $F$ BODIPY 1 gave a complex mixture of products when reacted with diacids $\mathbf{e}$ and $\mathbf{f}$ (probably oligomeric BODIPYs with 4,4'-diacyloxy bridges, as observed by MALDI-TOF analysis in the case of diacid e: see Figure S1 in Supporting Information) without formation of the corresponding BODIPYs 1e or 1f. In contrast, $F$-BODIPY 2, which lacks substituents at C-3 and C-5, readily reacted with $\mathbf{e}$ to give $\mathbf{2 e}$ in moderate yield, but afforded a complex mixture of products with the more sterically hindered 2,2dimethylmalonic acid $\mathbf{f}$ without formation of the expected $\mathbf{2 f}$. The procedure proved also successful with other dicarboxylic acids (with oxalic acid: 1g), hydroxy acids (with salicylic acid: $\mathbf{1 h}$ ), and monocarboxylic acids (with 2-chloroacetic acid: $\mathbf{2} \mathbf{i}$ and $\mathbf{2} \mathbf{j}$ ). In the later case, a small amount of the corresponding 4-fluoro-4-(2-chloroacetoxy)-derivative $\mathbf{2 i}$ was also isolated. Compounds $\mathbf{1} \mathbf{h}$ and $\mathbf{2} \mathbf{i}$, which have an asymmetric substitution pattern on boron, show different chemical shifts for the signals of the two ortho-methyl substituents of 
the phenyl ring. This chemical anisotropy reveals that the mesityl substituent is twisted out of the plane of the boradiazaindacene chromophore in solution in the series of BODIPYs studied, as observed also in the solid state by X-ray diffraction (see below).

X-Ray crystallography. Appropriate crystals for X-ray diffraction study were obtained by slow evaporation of $\mathrm{CH}_{2} \mathrm{Cl}_{2} /$ hexane or EtOAc/hexane solutions of compounds 1a-d, $\mathbf{1 f}, \mathbf{1 h}$, 2b, 2e, and 4a. The crystal structures and selected structural parameters (Table S1) are presented in the Supporting Information. The central six-membered $\mathrm{C}_{3} \mathrm{~N}_{2} \mathrm{~B}$ ring in this series of compounds deviate little from planarity, with respective mean and maximum deviations within 0.010-0.048 $\AA$ and 0.011-0.085 $\AA$ except for compound 4a, with a mesomethyl group, which showed the largest deviations in this series $(0.064 \AA$ and $0.126 \AA$, respectively). Interestingly, the planarity of the $\mathrm{C}_{3} \mathrm{~N}_{2} \mathrm{~B}$ ring, and, with this, that of the boradiazaindacene chromophore, increases with the ring-size of the cycloalkyl moiety of the malonate substituent $(\mathbf{1 a}<\mathbf{1 b}<\mathbf{1 c}<\mathbf{1 d} ; \mathbf{2} \mathbf{b}<\mathbf{2} \mathbf{e})$, irrespective of the degree of alkylation of the chromophore. The solid-state structures exhibited in all cases the expected quasi-orthogonal spatial disposition of the mesityl and dioxaborinane rings with respect to the central dipyrromethene chromophore (measured dihedral angles between the corresponding least-squares mean planes were within $70.0^{\circ}-89.1^{\circ}$ and $84.3^{\circ}-89.4^{\circ}$, respectively) (see Figure 4). The $\mathrm{N}-\mathrm{B}$ distances (1.53-1.55 $\AA$ ) were similar to that of the parent $F$-BODIPY $1(1.54 \AA),{ }^{[26]}$ indicating the usual delocalization of charge throughout the chromophore. With the only exception of compound $2 \mathrm{e}$, the $\mathrm{O}-\mathrm{B}$ distances (1.45-1.48 $\AA)$ were found to be roughly within the range (1.46-1.49 $\AA$ ) described for related $O$ BODIPYs with open-chain acyloxy substituents on boron, ${ }^{[12 a, b]}$ but longer than those of $O$ BODIPYs with dialkoxy substituents (1.41-1.44 $\AA) .{ }^{[11 c, 21]}$ In the case of $\mathbf{2 e}$, which has the 
most sterically hindered diacyloxyl group, the two $\mathrm{O}-\mathrm{B}$ bonds have rather different lengths (1.412(4) $\AA$ and 1.521(7) $\AA$ ), both out of the range observed for the other compounds in the series. This probably reflects the dissimilar steric repulsion exerted by the chair-like cyclohexyl group onto the two nearby carbonyl oxygens, as revealed also by the corresponding $\mathrm{C}-\mathrm{C}=\mathrm{O}$ bond angles $\left(123.5^{\circ}\right.$ vs. $120.8^{\circ}$ for the shorter and longer $\mathrm{CO} O-B$ bonds, respectively). The values of the $\mathrm{N}-\mathrm{B}-\mathrm{N}\left(105.6^{\circ}-107.5^{\circ}\right)$ and $\mathrm{O}-\mathrm{B}-\mathrm{O}$ $\left(109.8^{\circ}-114.0^{\circ}\right)$ angles were close to the ideal tetrahedral value and comparable to the corresponding $\mathrm{N}-\mathrm{B}-\mathrm{N}\left(107.2^{\circ}\right)$ and $\mathrm{F}-\mathrm{B}-\mathrm{F}\left(109.2^{\circ}\right)$ values reported for the parent $F$ BODIPY 1. The only exception in this regard was compound $\mathbf{2} \mathbf{j}$ with chloroacetoxy substituents on boron, which presented a smaller $\mathrm{O}-\mathrm{B}-\mathrm{O}$ angle $\left(101.3^{\circ}\right)$ as reported for other BODIPYs with acyloxy substituents $\left(101.0^{\circ}-101.8^{\circ}\right) .^{[12 a, b]}$ The $s$-cis conformation around the $\mathrm{OC}-\mathrm{OB}$ bond observed in this compound (and in similar $O$-BODIPYs ${ }^{[12 a, b]}$ with open chain acyloxy substituents on boron) places both carbonyl groups symmetrically folded over the $\pi$-system of the chromophore thus closing the $\mathrm{O}-\mathrm{B}-\mathrm{O}$ angle to minimize electronic repulsions. This repulsive interaction is absent in the $B$-spiranic 4,4-diacyloxyBODIPYs here studied due to the s-trans orientation around the $\mathrm{OC}-\mathrm{OB}$ bond imposed by the $B$-diacyloxy ring geometry in these compounds. 
(a)

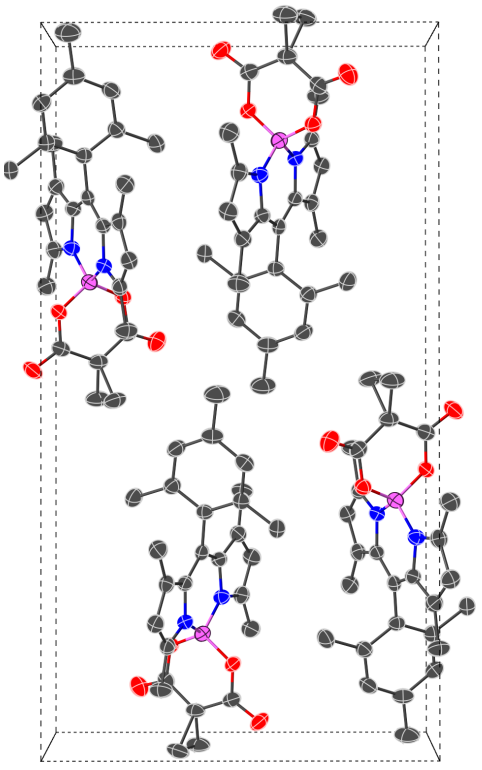

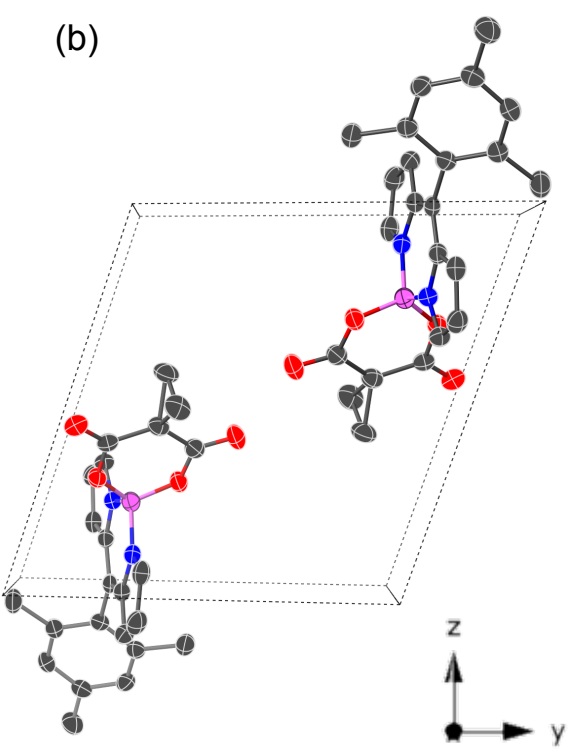

Figure 4. Crystal structures and crystal packing of compounds $\mathbf{1 b}$ (a) and $\mathbf{2 b}$ (b) from Xray diffraction studies. Hydrogen atoms have been removed for clarity.

In the crystalline packing arrangements observed for this series of $O$-BODIPYs, intermolecular $\mathrm{CH} \cdots \mathrm{O}$ hydrogen bondings are the most important forces, which play the role of the usual intermolecular $\mathrm{CH} \cdots \mathrm{F}$ hydrogen bonding interactions generally described for F-BODIPYs. Figure 4 shows the packing diagrams for two representative compounds (1b and 2b) sharing the same diacyloxyl group, but with different alkyl substitution patterns on the BODIPY core. These compounds are archetypical examples of the two divergent lasing properties observed in this series of $O$-BODIPYs (see below). For compound $\mathbf{1 b}$, there are two symmetrically disposed dimers in one crystal cell. The molecules in the dimer are connected through antiparallel head to tail interactions via mutual $\mathrm{CH} \cdots \mathrm{O}$ hydrogen bonds involving an aromatic hydrogen and an ortho-methyl of the mesityl group, together with $\mathrm{CH} \cdots \mathrm{N}(\pi)$ interactions of the same ortho-methyl group. These mutual interactions strengthen a slipped-skew relative arrangement of the molecules in the 
dimer with the two boradiazaindacene mean planes forming an angle of $56.16^{\circ}$ and separated by a $6.798 \AA$ distance, measured from the centroids of the respective C3N2B rings. In the case of $\mathbf{2 b}$, there are two equivalent molecules in the unit cell with a slipped head to tail relative orientation and with parallel boradiazaindacene planes. The solid state structure is stabilized by a network of $\mathrm{CH}^{\cdots} \mathrm{O}$ hydrogen bonds involving $\mathrm{C} 2-\mathrm{H}$ and $\mathrm{C} 3-$ $\mathrm{H}$ of the boradiazaindacene system and the para and one ortho-methyl of the mesityl group, together with $\mathrm{CH} \cdots \mathrm{N}(\pi)$ interactions involving the other ortho-methyl group. The distance between the closest neighbor molecules measured from the centroids of the respective C3N2B rings is $6.524 \AA$.

Lasing properties. All the new BODIPY dyes herein synthetized exhibited highly efficient and stable laser emission under transversal pumping at $355 \mathrm{~nm}$ (Table 1). As already observed for other $O$-BODIPYs,${ }^{[11 \mathrm{~b}]}$ the new dyes exhibit enhanced laser action with respect to their fluorinated parent dyes. Pumped under identical experimental conditions, lasing efficiencies up to 2 times higher than those recorded for the corresponding $F$ BODIPYs are registered with higher photostabilities since the laser output remains at $70 \%$ of its initial value after 100000 pump pulses at a repetition rate of $30 \mathrm{~Hz}$, while the corresponding fluorinated dye entirely loses its laser action after only 50000 pump pulses. In addition and most remarkably, the laser efficiency and spectrum of some of the new dyes exhibited an unusual dependence on common experimental parameters such as dye concentration.

Table 1. Laser parameters ${ }^{\text {a) }}$ of the new $O$-BODIPYs as a function of dye concentration in ethyl acetate solutions under transversal excitation at $355 \mathrm{~nm}$ with $4 \mathrm{~mJ} /$ pulse. 


\begin{tabular}{|c|c|c|c|c|c|c|c|c|c|}
\hline \multirow[b]{2}{*}{ Compound } & & \multicolumn{8}{|c|}{$[\mathrm{C}](\mathrm{mM})$} \\
\hline & & 8 & 6 & 4 & 2 & 1 & 0.8 & 0.5 & 0.2 \\
\hline \multirow[t]{2}{*}{$1 \mathbf{a}$} & Eff (\%) & 33 & 41 & 45 & 47 & 42 & 35 & 27 & 15 \\
\hline & $\lambda(\mathrm{nm})$ & 547 & 546 & 546 & $542 /(527)$ & $(542) / 527$ & 525 & 523 & 521 \\
\hline \multirow[t]{2}{*}{ 1b } & Eff $(\%)$ & 38 & 43 & 47 & 49 & 47 & 38 & 26 & 20 \\
\hline & $\lambda(\mathrm{nm})$ & 548 & 548 & 546 & 546 & 545 & $541 /(529)$ & 526 & 524 \\
\hline \multirow[t]{2}{*}{$1 c$} & Eff (\%) & 38 & 44 & 47 & 49 & 51 & 46 & 33 & 22 \\
\hline & $\lambda(\mathrm{nm})$ & 547 & 546 & 545 & 545 & 544 & $541 /(528)$ & $(541) / 528$ & 525 \\
\hline \multirow[t]{2}{*}{$1 d$} & Eff $(\%)$ & 33 & 38 & 41 & 45 & 47 & 41 & 32 & 18 \\
\hline & $\lambda \mathrm{nm}$ & 546 & 546 & 545 & 543 & 543 & $540 /(529)$ & $(540) / 528$ & 526 \\
\hline \multirow[t]{2}{*}{$1 \mathrm{~g}$} & Eff (\%) & 39 & 46 & 50 & 54 & 47 & 30 & 22 & 13 \\
\hline & $\lambda(\mathrm{nm})$ & 549 & 547 & 545 & $540 /(527)$ & $(540) / 527$ & 525 & 524 & 522 \\
\hline \multirow[t]{2}{*}{$1 \mathrm{~h}$} & Eff (\%) & 33 & 39 & 45 & 47 & 42 & 36 & 20 & 10 \\
\hline & $\lambda(\mathrm{nm})$ & 547 & 546 & 545 & 544 & $(542) / 529$ & $541 /(529)$ & 525 & 523 \\
\hline \multirow[t]{2}{*}{$2 b$} & Eff (\%) & 18 & 30 & 40 & 55 & 53 & 46 & 37 & 28 \\
\hline & $\lambda(\mathrm{nm})$ & 530 & 528 & 528 & 527 & 526 & 525 & 525 & 524 \\
\hline \multirow[t]{2}{*}{$2 e$} & Eff (\%) & 25 & 33 & 44 & 51 & 49 & 40 & 36 & 21 \\
\hline & $\lambda(\mathrm{nm})$ & 528 & 526 & 525 & 525 & 523 & 522 & 522 & 520 \\
\hline \multirow[t]{2}{*}{$2 \mathbf{j}$} & Eff (\%) & 25 & 35 & 42 & 38 & 34 & 30 & 23 & 17 \\
\hline & $\lambda(\mathrm{nm})$ & 529 & 527 & 526 & 526 & 525 & 525 & 524 & 524 \\
\hline \multirow[t]{2}{*}{$3 \mathbf{a}$} & Eff (\%) & 15 & 20 & 27 & 24 & 22 & 16 & 10 & - \\
\hline & $\lambda(\mathrm{nm})$ & 575 & 573 & 570 & 568 & 567 & 565 & 563 & - \\
\hline \multirow[t]{2}{*}{$4 a$} & Eff (\%) & 18 & 29 & 35 & 40 & 36 & 30 & 23 & - \\
\hline & $\lambda(\mathrm{nm})$ & 541 & 539 & 538 & 537 & 535 & 534 & 532 & - \\
\hline
\end{tabular}

a)Eff: energy conversion efficiency; $\lambda$ : peak wavelength of the laser emission; two peaks are observed once the bichromatic emission is established (the band with lower intensity is indicated in parenthesis).

Under the selected experimental conditions (transversal excitation and strong focusing of the incoming pump radiation), the concentration of the dyes should be in the 
millimolar range to ensure total absorption of the pump radiation within the first millimeter at most, in order to obtain an emitted beam with near-circular cross-section and optimize the lasing efficiency (ratio between the energy of the dye laser output and the pump energy incident on the sample surface). To determine the dye concentration that optimizes the laser emission of the different dyes, we first analyzed the dependence of their laser emission on the corresponding dye concentrations in ethyl acetate by varying the optical density (for a 1 $\mathrm{cm}$ optical path length) from 2 to 40 , while keeping all the other experimental parameters constant. Some of the new $O$-diacyl BODIPYs $(\mathbf{2} \mathbf{b}, \mathbf{2 e}, \mathbf{2} \mathbf{j}, \mathbf{3 a}$, and $\mathbf{4 a}$ ) followed the expected behavior, with lasing efficiency first increasing with dye concentration until a maximum value was reached. Increasing the dye concentration beyond this point resulted in a decrease in lasing efficiency that could be ascribed to reabsorption/reemission processes, which become increasingly important with increasing dye concentration (Table 1). However, the behavior of other derivatives such as 1a-d, $\mathbf{1 g}$, and $\mathbf{1 h}$ deviated from the expected dependence. Like $O$-diacyl BODIPYs $\mathbf{2 b}, \mathbf{2 e}, \mathbf{2} \mathbf{j}, \mathbf{3 a}$, and $\mathbf{4 a}$, the highest laser efficiency was obtained at a moderate concentration of ca. $2 \mathrm{mM}$, but they exhibited a less pronounced reduction in laser efficiencies at the highest concentrations, even when they were clearly operating under non-optimal experimental conditions as indicated by the cross-section of the emitted beam not being near-circular but shaped as a narrow vertical ellipse. Remarkably, the effect of the increased reabsorption/reemission processes usually associated to high concentrations was not so significant and, although both processes work cooperatively to reduce the laser efficiency, these dyes maintained high laser efficiencies at the highest concentration range. 


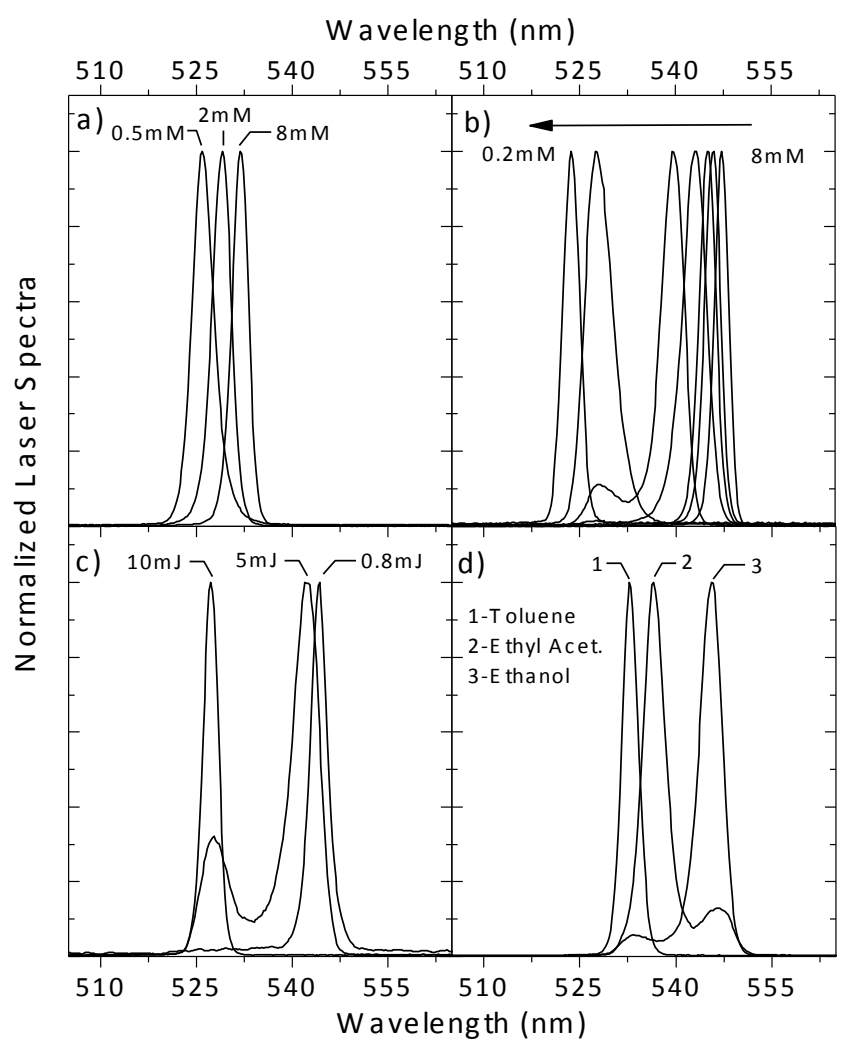

Figure 5. a) Laser spectra of dye $\mathbf{2 b}$ in ethyl acetate as a function of dye concentration. b)d) Laser spectra of dye $\mathbf{1 b}$ as a function of, respectively, dye concentration (in ethyl acetate), pump energy ( $1 \mathrm{mM}$ in ethyl acetate), and solvent polarity ( $0.5 \mathrm{mM})$. Pump energy in a), b) and d) is $4 \mathrm{~mJ} /$ pulse.

In addition, unusual features emerged when analyzing the dependence of the laser emission spectrum on the dye concentration. Thus, the laser spectra recorded from the ethyl acetate solutions of dyes $\mathbf{2 b}, \mathbf{2 e}, \mathbf{2 j}, \mathbf{3 a}$, and $\mathbf{4 a}$ followed again the expected behavior, with the laser peak wavelength being slightly blue-shifted as the concentration decreases, due to the reduction in reabsorption/reemission effects (Figure 5a and Table 1). Following a quite different behavior, the laser spectra of dyes $\mathbf{1}, \mathbf{1 a - d}, \mathbf{1 g}$, and $\mathbf{1 h}$ exhibited two distinct emission bands, at $540 \mathrm{~nm}$ and $528 \mathrm{~nm}$, whose relative strength depended on the particular 
dye concentration (Figure $5 \mathrm{~b}$ and Table 1). At the highest concentrations, the longwavelength emission band dominated the spectrum while at moderate concentrations (around $1 \mathrm{mM}$ ), there was a clear bichromatic emission. The short-wavelength band of this bichromatic emission kept on growing as the dye concentration decreased, with the laser spectrum eventually becoming a single-peak emission centered at $526 \mathrm{~nm}$.

In the light of the above results, some hypothesis could be ventured to explain this unexpected behavior, including the emergence of reabsorption/reemission effects or the presence of supramolecular species, such as J-aggregates, dimers or excimers, all of them red-shifting the emission band and enabling, in some cases, bichromatic emission. ${ }^{[27]}$ But in order to gain a better insight into the origin of the bichromatic emission, more detailed studies would be required. Thus, we proceeded to systematically analyze the dependence of the laser spectral profile on different experimental parameters, such as pump intensity, cavity configuration, dye structure, and solvent polarity.

A) Pump intensity. This effect was studied in a dye solution where the dual emission was already well established at low pump intensity. A $0.5 \mathrm{~mm}$ solution of dye $\mathbf{1 b}$ in ethyl acetate fulfilled this condition. The relative intensity of the two peaks at 540 and $526 \mathrm{~nm}$ observed in the laser emission varied drastically with pump intensity (Figure 5c). Most strikingly, lowering pump intensities resulted in a significant increase of the $540 \mathrm{~nm}$ peak and a decrease of the $526 \mathrm{~nm}$ peak, up to its total disappearance when the pump intensity was set below $1 \mathrm{~mJ} /$ pulse. Conversely, going to higher pump intensities resulted in an increase of the $526 \mathrm{~nm}$ band, which became first the main and then the single peak at 10 $\mathrm{mJ} / \mathrm{pulse}$. 
This dependence on the pump energy was substantiated by analyzing the threshold energy of each of the bands present in the laser spectrum. Surprisingly, the longwavelength peak exhibited noticeable low threshold energy (ca. $0.05 \mathrm{~mJ} /$ pulse), 10-fold lower than that of any other organic laser dye when pumped under identical experimental conditions. On the contrary, the short-wavelength laser band exhibited remarkably high threshold energy $(1.2 \mathrm{~mJ} /$ pulse $)$, much higher than those recorded from any type of organic dye pumped under identical experimental conditions.

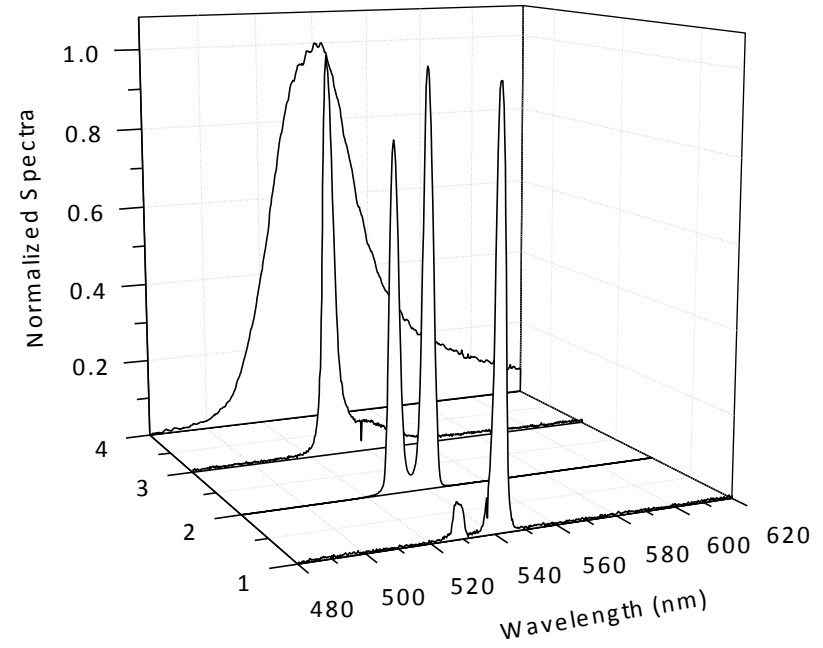

Figure 6. Emission spectra of dye $\mathbf{1 b}(1 \mathrm{~mm})$ in ethyl acetate solution transversally pumped with $4 \mathrm{~mJ} /$ pulse placed in the full cavity (1); with the rear mirror removed (2), contained in a triangular cell (3), and pumped in front-face configuration (4). For pump and cavity configurations, see Figure S2 in Supporting Information.

These experiments with the pump energy could allow ruling out excimers (or superexciplex) and ground-state dimers as the species responsible for the long wavelength 
band since, as it has been previously reported, in those cases this band is absent at low pump energies but dominant at high pump energies. ${ }^{[27]}$

b) Cavity configuration. Spectral profiles were measured in a modified cavity configuration, which allows reducing the feedback in a controlled way in order to probe the dependence of the dual emission on the amount of optical gain (Figure 6). Under pump intensity at which the peak at $540 \mathrm{~nm}$ dominated the lasing emission of dye $\mathbf{1 b}$, the rear mirror of the cavity was removed. In this way, the cuvette windows acted as feedback elements and, thereby, the cavity length shortened from 2 to $1 \mathrm{~cm}$ (see Figure S2b in Supporting Information). Under these conditions, the spectrum evolved to a bichromatic emission with bands of similar intensity. Next, to minimize the feedback in the cell windows and further reduce the optical gain, the solution was placed in a triangular quartz cell (Figure S2c), which led the spectrum to evolve to a single-band peaked at $526 \mathrm{~nm}$ with a weak shoulder at $540 \mathrm{~nm}$. Finally, when the optical gain was drastically reduced by implementing a front-face configuration, where the pumping area was concentrated to a circular spot of $300 \mu \mathrm{m}$ diameter and the emission was collected normal to the cuvette window (Figure S2d), the laser-induced fluorescence emission showed a broad-band spectrum centered at $540 \mathrm{~nm}$, with only slight traces of the emission at $520 \mathrm{~nm}$. Only when the concentration was reduced, did the fluorescence emission band shift to $520 \mathrm{~nm}$ (Figure S3). This behavior reveals that, only under high optical gain pump and cavity configurations does the $540 \mathrm{~nm}$-peaked emission emerge as the single or dominant band in the laser spectrum.

Each of the laser bands featured dissimilar tuning capabilities. Placing the solution in a grazing-incidence grating tunable resonator (Figure S2e), the short-wavelength band at $526 \mathrm{~nm}$ enabled a tuning range of $30 \mathrm{~nm}(515-540 \mathrm{~nm})$, which is the usual tunability span 
of laser dyes. In contrast, the long-wavelength laser band could be only tuned within a much narrower $5 \mathrm{~nm}$ range $(542-547 \mathrm{~nm})$, which is a "fingerprint" of J-aggregates.

c) Dye structure. The availability of $O$-diacyl-BODIPYs with different degrees of substitution enabled us to establish a clear dependence of the laser spectral features on the structure of the dye. Thus, regardless of the experimental conditions, bichromatic laser emission was never observed in solutions of:

- BODIPYs unsubstituted at C-1, C-3, C-5, and C-7, independently of the substituent group on boron being either fluorine atoms (dye 2), diacyoxyl (dyes $\mathbf{2 b}$ and $\mathbf{2 e}$ ) or monoacyloxyl groups (dyes $\mathbf{2 i}$ and $\mathbf{2} \mathbf{j}$ ).

- $O$-BODIPYs with methyl substituents at C-1, C-3, C-5, and C-7, but with an 8mesityl group replaced by a less bulky substituent such as a methyl group (dye $\mathbf{4 a )}$ ).

- $O$-BODIPYs with all positions substituted (dye 3a).

In addition, bichromatic laser emission was only observed for solutions of dyes that present all the following structural features: i) methyl substituents at positions $1,3,5$, and 7 , ii) positions 2 and 6 unsubstituted, and iii) a sterically hindered mesityl group at position 8, independently of the nature of the substituent groups on boron being either fluorine atoms (dye 2) or $O$-acyl groups.

Furthermore, the critical concentration required to grow the bichromatic emission depended on the $O$-diacyl group grafted to boron. Thus, in the fluorinated dye $\mathbf{1}$ and in dyes 1a and 1g, with the smallest $O$-diacyl substituents, dual emission was observed at concentrations below $2 \mathrm{mM}$, while lower concentratios $(0.8 \mathrm{mM})$ were required to start 
raising a bichromatic emission in the laser spectra of $\mathbf{1 b}, \mathbf{1 c}, \mathbf{1 d}$, and $\mathbf{1 h}$ dyes, with bulkier $O$-diacyl substituents on boron.

d) Solvent polarity. To properly analyze the actual effect of the solvent on the evolution of the laser spectra, the new dyes were dissolved in polar protic (ethanol), polar aprotic (ethyl acetate), and apolar (cyclohexane) solvents. However, the low solubility of the dyes in the latter solvent prevented attaining concentrated solutions, forcing us to use a slightly more polar solvent, such as toluene. In this case, the solvent polarity becomes the key factor, but neither the protic or aprotic character of the solvent nor the dye solubility in each solvent seemed to play any relevant role on the observed laser properties. In fact, the higher the polarity of the solvent, the lower the critical concentration to establish the bichromatic emission was required (Figure 5d).

The phenomenological features described above provided meaningful arguments to attribute the origin of the long-wavelength band observed in the laser spectra to selfassemble of the new dyes into J-aggregates, whose emission is red-shifted with respect to that of the monomeric unit. The distinctive properties of J-aggregates are convincing evidence to rule out the existence of any other type of aggregation either in the ground (dimers, trimers, and higher oligomers) or excited (excimers or superexciplexes) states. Thus, the high laser efficiencies recorded at high concentrations and the low threshold energy for laser emission as well as the dependence of the laser bichromatic emission on the pump intensity can only be explained by the superradiance characteristic of Jaggregates. ${ }^{[28]}$ Our results pinpoint the coexistence of both, monomers (emission at 525 $\mathrm{nm}$ ) and J-aggregates (emission at $540 \mathrm{~nm}$ ), with a seemingly predominance of the former. In this sense, J-aggregates present a much lower threshold and, hence, they can lase at low 
pump energies only. As the pump energy is increased, more J-aggregates are excited and hence their emission is enhanced, but monomers may cross the threshold and start lasing simultaneously. With a further increase in pump energy, J-aggregate emission saturates due to the small amount of active centers available, while the high abundance of monomers allows their emission to grow further, surpassing and, eventually, quenching the Jaggregates emission. In other words, at high pump energies the deactivation rate due to stimulated emission of the monomer is much larger than the J-aggregate formation rate, and, thus, the monomer emission prevails in the final spectrum.

One of the most important issues concerning the optical properties of J-aggregates relates to what is termed optical coherent length of the aggregate, ${ }^{[29]}$ which corresponds basically to the number of monomers over which the excitation wavefunction is delocalized. The extended domains of coherently coupled molecular transition moment account for the very narrow tuning range proper of J-aggregates as well as for the origin and unique features of the unexpected spectral modulation depending on the cavity configuration. Thus, the greater the feedback induced into the cavity, the larger the delocalization length becomes and, consequently, in the plane-parallel full cavity, laser efficiency becomes higher and the spectral bands narrower. In addition, the coupling of transition dipoles of neighboring molecules requires an environment that facilitates the process. Hence, the greater the dipole moment of the dye and the higher the solvent polarity, the lower becomes the critical concentration to J-aggregate. Once the experimental conditions fulfill the required pump fluence, dye concentration, and cavity configuration, fast and efficient Jaggregation suppresses laser emission from single dye molecules. In this way and for the first time to the best of our knowledge, we registered highly efficient and stable laser 
emission from J-aggregated organic dyes in organic solvents without any additive. Key to the effectiveness of the process is the design of the new dyes, the high intensity and coherence of the pump laser radiation as well as the feedback provided by the resonant cavity.

Photophysical characterization and atomistic simulations of the new BODIPY dyes enable to better understand this unprecedented J-aggregation process and its dependence on dye structure, environmental and pumping conditions.

Photophysical studies. Dyes 1a-1d, 1g-1h, and 2b, 2e showed similar photophysical signatures (Table 2), albeit in the two latter compounds the chromophoric core is not methylated. Thus, the 8-mesityl substituent provided a high enough steric hindrance as to prevent the negative effect that a free moving aryl group would produce on the fluorescence response. In fact, both sets of dyes outstand by their high fluorescence, peaked at around 510-515 nm, which surpassed 90\% quantum yield (some of them even approaching 100\%), due to a low probability of non-radiative relaxation, as a consequence of the rigid and constrained molecular structure promoted by the bulky rings grafted at both the meso position and the boron atom. The suitability of the spiranic $O$-BODIPY ${ }^{[17 c]}(\mathbf{1 a - 1 d}$ and $\mathbf{1 g}-$ 1h) was clearly demonstrated by the direct comparison with their parent $F$-BODIPY 1. Although, they kept very similar photophysical signatures, the fluorescence efficiency was overall slightly improved upon the replacement of the fluorine atoms by the diacyloxy ring. Therefore, the high laser efficiency (Table 1) attained for the BODIPYs bearing 8-mesityl and $B$-diacyloxy rings are fully reasonable. An exception to this rule is compound 3a, which showed a modest spectral bathochromic shift and reduced fluorescence quantum yield when compared to its parent PM567. ${ }^{[8]}$ This is probably due to the heavy atom effect 
induced by the bromine atom at the para position of the 8-phenyl ring (Table 2), which also led to a lower laser efficiency (Table 1). The diacyl open-chain derivatives $\mathbf{2} \mathbf{i}$ and $\mathbf{2} \mathbf{j}$ showed slightly lower fluorescence efficiency ( $84 \%$ in Table 2$)$ than the other $O$-BODIPYs, which might be related to a higher flexibility of the $O$-substituents on boron, again underscoring the positive effect of the $B$-spiranic molecular design. Nevertheless, both dyes were still highly fluorescent and yielded good laser performance (Table 1), in agreement with the published results for structurally related $O$-BODIPYs. ${ }^{[11 \mathrm{~b}]}$ Regarding the solvent polarity effect, the new $O$-BODIPYs followed the same trends previously reported for structurally related dyes (see our reference [11b] for $O$-BODIPYs with open-chain alkoxy groups at the boron atom) that are also similar to the behavior of typical $F$-BODIPYs, such as small hipsochromic spectral shifts, low sensibility of the absorption coefficient, lower fluorescence quantum yield and shorter lifetime with increasing solvent polarity.

Table 2. Photophysical properties of the new BODIPYs in diluted solutions in ethyl acetate: Absorption $\left(\lambda_{\mathrm{ab}}\right)$ and fluorescence $\left(\lambda_{\mathrm{fl}}\right)$ wavelengths, Stokes shift $\left(\Delta v_{\mathrm{St}}\right)$, molar absorption coefficients $\left(\varepsilon_{\max }\right)$, fluorescence quantum yields $(\phi)$ and lifetimes $(\tau)$, as well as radiative $\left(\mathrm{k}_{\mathrm{fl}}\right)$ and non-radiative $\left(\mathrm{k}_{\mathrm{nr}}\right)$ rate constants.

\begin{tabular}{ccccccccc}
\hline Dye & $\lambda_{\mathrm{ab}}$ & $\varepsilon_{\mathrm{max}}$ & $\lambda_{\mathrm{fl}}$ & $\Delta \mathrm{v}_{\mathrm{St}}$ & $\phi$ & $\tau$ & $\mathrm{k}_{\mathrm{fl}}$ & $\mathrm{k}_{\mathrm{nr}}$ \\
& $(\mathrm{nm})$ & $\left(10^{4} \mathrm{M}^{-1} \mathrm{~cm}^{-1}\right)$ & $(\mathrm{nm})$ & $\left(\mathrm{cm}^{-1}\right)$ & & $(\mathrm{ns})$ & $\left(10^{8} \mathrm{~s}^{-1}\right)$ & $\left(10^{8} \mathrm{~s}^{-1}\right)$ \\
\hline $\mathbf{1}$ & 500.0 & 10.2 & 508.0 & 315 & 0.92 & 5.67 & 1.62 & 0.14 \\
$\mathbf{1 a}$ & 503.0 & 7.0 & 510.0 & 275 & 0.94 & 6.20 & 1.52 & 0.10 \\
$\mathbf{1 b}$ & 503.0 & 8.4 & 511.5 & 330 & 0.94 & 6.28 & 1.50 & 0.10 \\
\hline
\end{tabular}




\begin{tabular}{ccccccccc}
\hline $\mathbf{1 c}$ & 503.0 & 8.0 & 511.0 & 310 & 0.90 & 6.35 & 1.42 & 0.16 \\
$\mathbf{1 d}$ & 503.0 & 8.6 & 511.0 & 310 & 0.90 & 6.44 & 1.40 & 0.16 \\
$\mathbf{1 g}$ & 505.5 & 8.0 & 513.0 & 290 & 0.96 & 6.44 & 1.49 & 0.06 \\
$\mathbf{1 h}$ & 503.5 & 8.3 & 512.0 & 330 & 0.92 & 6.22 & 1.48 & 0.13 \\
$\mathbf{2 b}$ & 503.0 & 6.9 & 514.5 & 444 & 0.89 & 7.72 & 1.15 & 0.14 \\
$\mathbf{2 e}$ & 503.5 & 5.3 & 516.5 & 500 & 0.98 & 7.98 & 1.23 & 0.03 \\
$\mathbf{2 i}$ & 501.0 & 5.6 & 512.0 & 430 & 0.84 & 8.22 & 1.02 & 0.19 \\
$\mathbf{2 j}$ & 501.5 & 7.2 & 512.0 & 410 & 0.84 & 8.46 & 0.99 & 0.19 \\
$\mathbf{3 a}$ & 528.5 & 5.9 & 541.0 & 440 & 0.53 & 4.39 & 1.21 & 1.07 \\
$\mathbf{4 a}$ & 496.5 & 5.2 & 508.0 & 455 & 0.83 & 6.11 & 1.36 & 0.28 \\
\hline
\end{tabular}

The most striking and intriguing feature of these novel $O$-BODIPYs is the above explained dual laser emission of the compounds bearing a methylated chromophoric core (see 1b vs. 2b in Figure 5). To unravel such unusual behavior and confirm the aforementioned formation of J-aggregates, we tested both the concentration effect and the addition of increasing amounts of water to ethanol solutions of two representative compounds: 1b, with bichromatic laser emission, and its structural non-alkylated analog $\mathbf{2 b}$, which showed only single laser emission. In spite of the high optical densities employed (up to $10 \mathrm{mM}$, close to the solubility limit, with optical pathways of 0.001 and $0.01 \mathrm{~cm}$ ) in an attempt to mimic the laser conditions, the recorded spectra matched those registered in diluted solutions (once corrected for reabsorption phenomena in the fluorescence spectra $^{[30]}$ ) (Figure S4). The absence of aggregation recording the photophysical properties of the new dyes in organic solvents has to be related to the low intensity and coherence of the excitation sources involved in these measurements. Once again, these results 
demonstrate that the high intensity and coherence of the pump laser radiation as well as the feedback provided by the resonant cavity are key factors to record efficiently J-aggregated emission.

Alternatively, aggregation could be induced by the progressive addition of water to ethanol solutions of the dyes due to the characteristic hydrophobicity of BODIPYs. ${ }^{[31]}$ In fact, whereas neither new bands nor shoulders (just a progressive lower absorbance) were recorded for compound $\mathbf{2 b}$ even in water-rich mixtures (up to $99 \% \mathrm{H}_{2} \mathrm{O}$ in ethanol, see Figure S5), severe spectroscopic changes were observed for its methylated analog $\mathbf{1 b}$ (Figure 7). Thus, for water content in the suspensions higher than $77 \%$, the absorption at $503 \mathrm{~nm}$ progressively decreased in favor of a new weak band at $550 \mathrm{~nm}$, which became dominant in the spectrum and entailed a clear yellow to pale red color change observed by the naked eye (Figure 7 and Figures S5 and S6). Accordingly, the excitation of $\mathbf{1 b}$ at the monomeric absorption, assigned to the band at $503 \mathrm{~nm}$, led to its own emission centered at $510 \mathrm{~nm}$, although much less intense than that recorded in pure organic solvent, together with an additional weak red-shifted emission at $555 \mathrm{~nm}$, whose intensity slightly increased with the water content in the solution until it became the main band of the emission spectrum. Such new long-wavelength fluorescence signal was attributed to an aggregationinduced emission. In particular, it is assigned to J-aggregates, which are characterized by allowed transitions at lower energies than the monomer and usually provide their own fluorescence signal. However, this J-aggregate formed in aqueous media has a poor fluorescence and leads to an efficient static quenching of the monomer emission (the overall fluorescence efficiency drops from $90 \%$ in ethanol to $6 \%$ in $90 \%$ water mixture, Figure S6). The fluorescence decay analysis confirms this trend since the lifetime 
monitored at the monomer emission $(510 \mathrm{~nm})$ remains similar to that attained in organic media (main lifetime around $6.61 \mathrm{~ns}$ in the mixture with a water content of $90 \%$ ), while the lifetime recorded at the J-aggregate emission $(550 \mathrm{~nm})$ is very short (main lifetime around $50 \mathrm{ps}$ ), indicating a large probability of non-radiative deactivation (Figure S7).
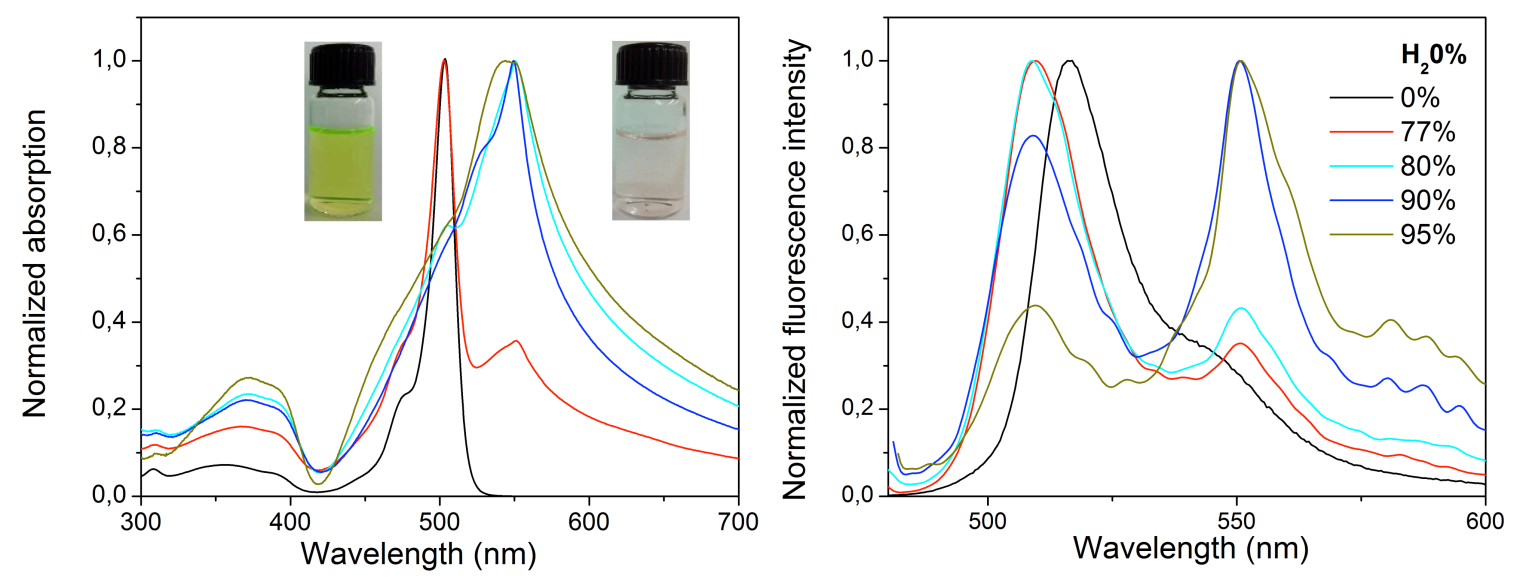

Figure 7. Normalized absorption and fluorescence spectra of dye $\mathbf{1 b}$ in water-ethanol mixtures $(10 \mu \mathrm{M})$. for a better visualization of the spectral changes promoted by aggregation. The non-normalized spectra are shown in Figure S6. Inset: photographs showing the color change of the solution from pure ethanol (green) to water-rich mixtures (light red).

These experimental trends are consistent with the formation of J-aggregates in $\mathbf{1 b}$, which are characterized by allowed transitions at lower energies than the monomer and usually provide their own fluorescence signal. Taking into account that its non-methylated counterpart $\mathbf{2 b}$ did not show new bands, it seems that J-aggregation is driven by steric effects. Thus, methylation at positions $1,3,5$ and 7 in compound $\mathbf{1 b}$ may hamper the stacking of the boradiazaindacene units in the interacting monomers (which could be more 
feasible in the unsusbtituted $\mathbf{2 b}$ ) and force the molecules to a head-tail interaction, which enables a J-type aggregation. All these experimental findings support J-aggregation as the origin of the dual emission detected in the laser gain media for BODIPYs bearing a methylated core.
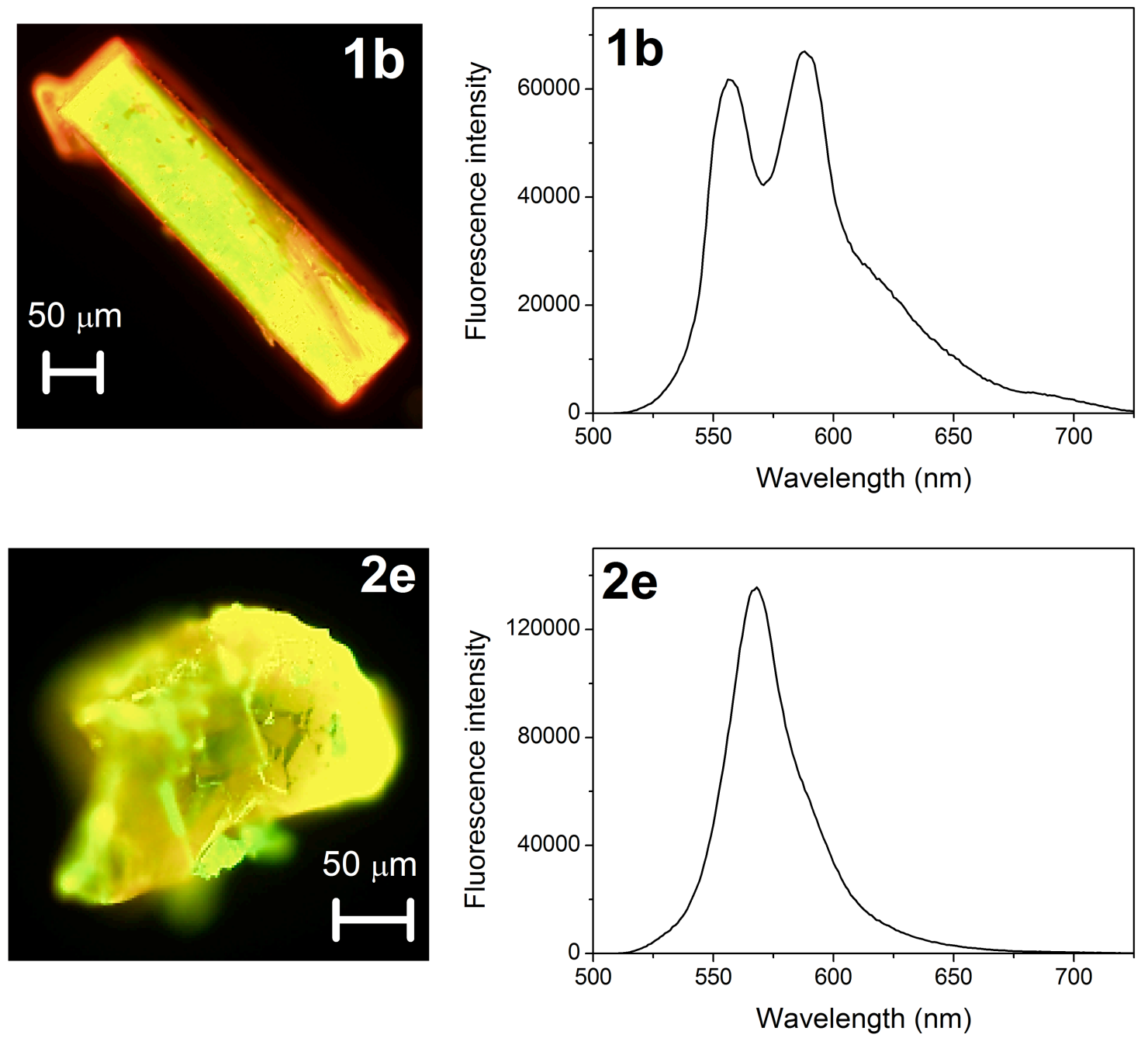

Figure 8. Fluorescence images and spectra of solid crystals of representative compounds 1b and 2e recorded under excitation at 450-490 $\mathrm{nm}$ with a fluorescence microscope. 
Another evidence for the unambiguous assignment of the J-aggregation process arises analyzing the solid-state emission properties of two representative dyes such as $\mathbf{1 b}$ (with J-aggregation capability) and 2e (remaining as monomeric units). Under UV light, the fluorescence of the solids is hardly visible by the naked eye. However, as shown in Figure 8, under the fluorescence microscope (with blue excitation at 450-490 nm) both crystals show fluorescence emission, but with very different efficiencies and spectral profiles. Thus, while 1b exhibited an intense fluorescence, reaching an absolute fluorescence quantum yield of $0.24 \%$, the fluorescence efficiency of $2 \mathrm{e}$ is so low that it could not be determined accurately. In addition, the corresponding fluorescence spectra are rather different. Whereas 2e exhibited a single emission corresponding to the monomer, in $\mathbf{1 b}$ a second longwavelength emission is also recorded, which is assigned to the corresponding J-aggregated form. Therefore, the head to tail disposition in $\mathbf{1 b}$ predicted theoretically and by X-ray diffraction, leads to formation of J-aggregates, which are not longer formed in $\mathbf{2 e}$ owing to the more stacked disposition of the monomeric units.

Atomistic simulations. To explain the above described bichromatic laser emission and the observed spectroscopic changes, we decided to simulate compound $\mathbf{1 b}$, which shows the Jtype emission, and its analog $\mathbf{2 b}$, using atomistic modeling. Starting from the crystalline structures provided by X-ray diffraction (see the packing arrangement provided by X-ray crystallography in Figure 4), we performed molecular dynamics (MD) simulations in the isothermal-isobaric (NPT) ensemble. The equilibrium lattice parameters and atomic positions obtained from the simulations matched well with the experimental data (Figure 4) and the obtained MD trajectories allowed us to analyze the molecular arrangements susceptible to form dimers. We searched for the angle $(\theta)$ formed by the vector connecting 
the center-of-mass of two molecules with the transition moment vector, which following Kasha's molecular exciton mode ${ }^{[32]}$ will define the dimer type, as well as the center-ofmass to center-of-mass distances $\left(\mathrm{d}_{\mathrm{CM}}\right)$, which will indicate the exciton coupling extent. The combined probability of these quantities between nearest neighboring molecules revealed three different arrangements susceptible to form dimers in crystals of compounds $\mathbf{1 b}$ and $\mathbf{2 b}$, denoted as coplanar, oblique, and collinear (Figure 9). Taking these molecular arrangements as starting points, we carried out an annealing simulation decreasing the temperature from $300 \mathrm{~K}$ to $1 \mathrm{~K}$ at a $0.3 \mathrm{~K} / \mathrm{ps}$ rate. Interestingly, the three initial dimeric configurations converged to the coplanar arrangement for both dyes, with slightly different distances between monomers depending on the compound, or in other words, depending on the methylation of the chromophore. At the equilibrium configurations, the dimer formed by $\mathbf{1 b}$ had a larger $d_{\mathrm{CM}}$ and lower $\theta$ than the dimer former by $\mathbf{2 b}$ (Figure 10). More importantly, the $\theta$ value in $\mathbf{1 b}$ dimers was $21^{\circ}$, which revealed an aggregation arrangement that comply with a J-type dimer, whereas in $\mathbf{2 b}$ dimers $\theta$ was $41^{\circ}$, closer to the limiting value between $\mathrm{J}$ and H-type aggregates. ${ }^{[32]}$ In $\mathbf{2} \mathbf{b}$, the boradiazaindacene units of the monomers are more coplanar and stacked because their proximity is not sterically hindered, while in $\mathbf{1 b}$ the molecules are also parallel but considerably more displaced due to the presence of the methyl groups, which hamper the stacking of the chromophores and move them away, leading to an orientation closer to a head-to-tail arrangement. 
(a)
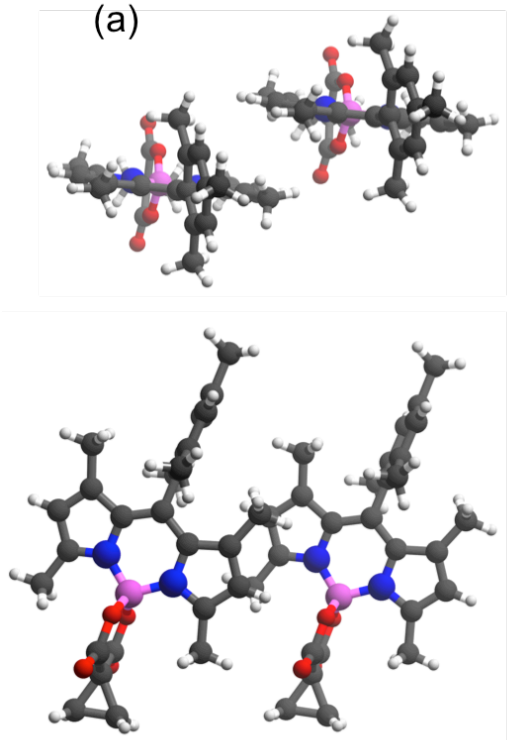

(b)
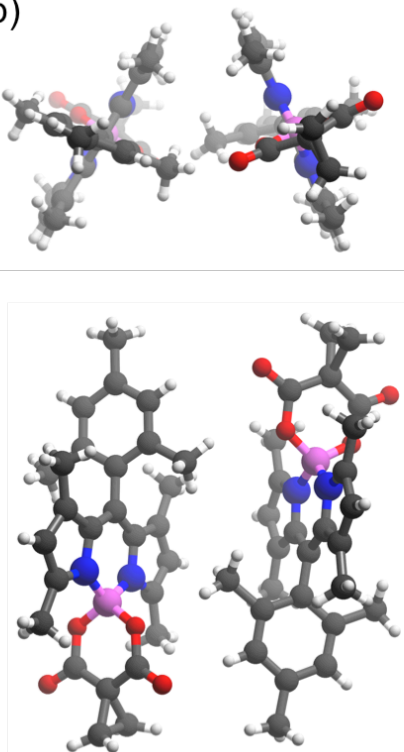

(c)
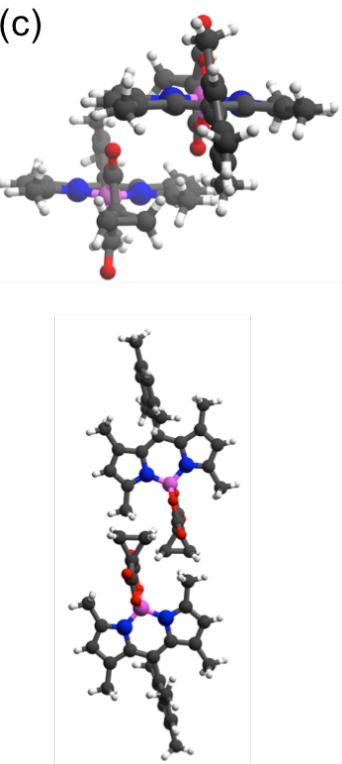

Figure 9. Representation of the (a) coplanar, (b) oblique, and (c) collinear arrangement of neighboring dye molecules in the $\mathbf{1 b}$ molecular crystal from top and parallel views. The grey, red, blue, pink, and white spheres represent $\mathrm{C}, \mathrm{O}, \mathrm{N}, \mathrm{B}$, and $\mathrm{H}$, respectively.

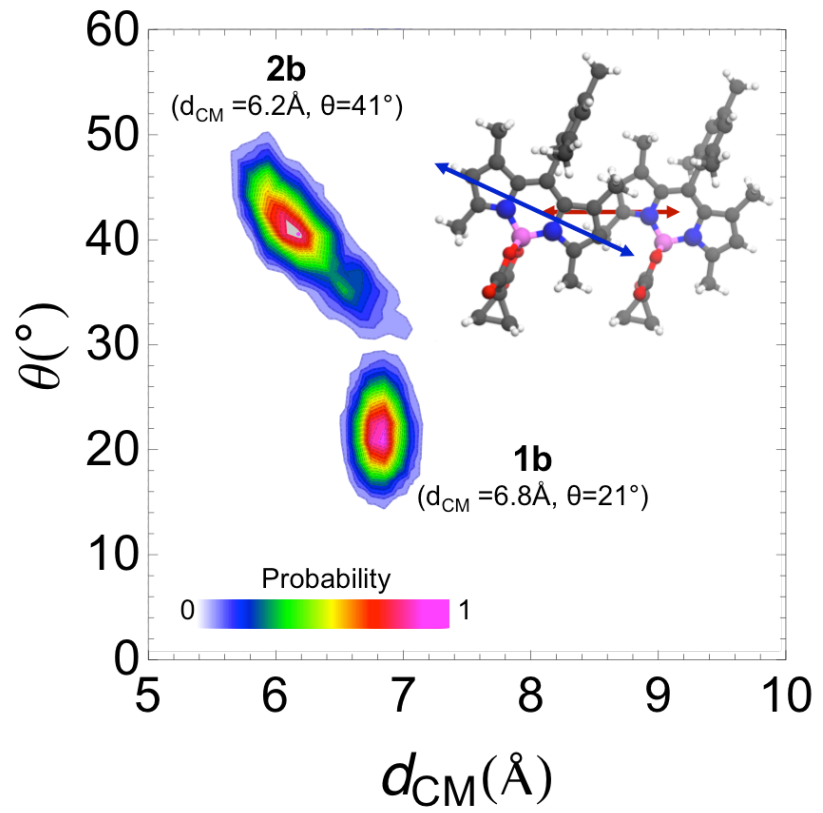


Figure 10. Normalized combined probability of center-of-mass to center-of-mass distances and $\theta$ angle for $\mathbf{1 b}$ and $\mathbf{2} \mathbf{b}$ dimers in vacuum. Two distinct distributions are shown, corresponding to each type of dimer. The optimized geometry of dimer $\mathbf{1 b}$ is included to show the vectors involved in the analysis: the $\mathrm{d}_{\mathrm{CM}}$ vector in orange, and the transition dipolar moment in green. The $\theta$ angle is formed by these two vectors.

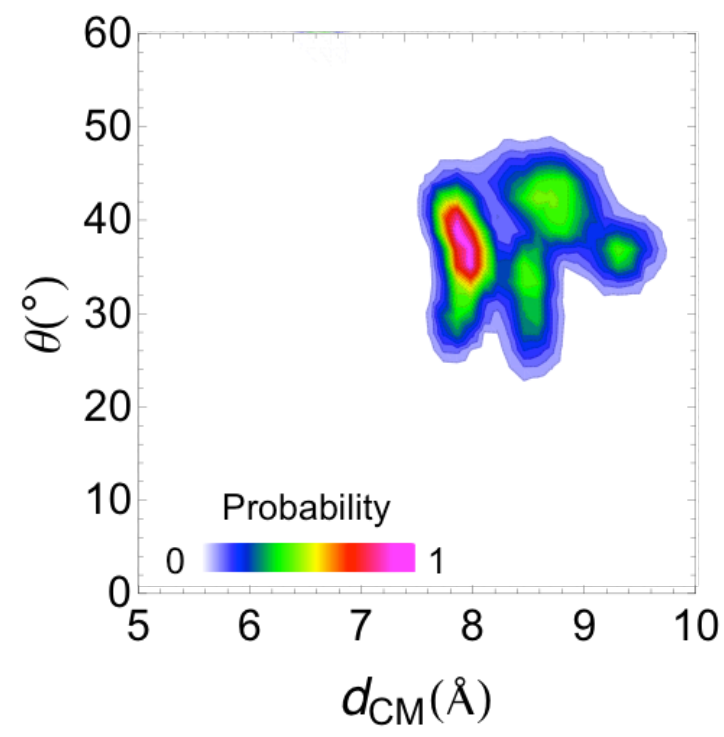

Figure 11. Normalized combined probability of center-of-mass to center-of-mass distances and $\theta$ angle averaged for 10 dimers of $\mathbf{1 b}$ in ethyl acetate.

Once checked that the most stable dimer configuration for compound $\mathbf{1 b}$ could lead to J-type dimers in vacuum, we simulated its aggregation geometry and stability in organic media, using ethyl acetate as the solvent. Ten previously optimized dimers were randomly introduced in a $20 \AA$ cubic box with 800 solvent molecules and a NPT simulation was 
conducted at room temperature and pressure. The simulation box adjusted its volume to reach an equilibrium density of $0.890 \mathrm{~g} / \mathrm{cm}^{3}$, close to the ethyl acetate density value. The essential outcome of the simulation was that the dimers remained aggregated during the 20 ns simulation, three times the fluorescence lifetime, which supported the experimental evidences for aggregation-induced emission. The most probable $d_{C M}$ distance increased with respect to the vacuum equilibrium value up to $7.8 \AA$, suggesting a weak exciton coupling (Figure 11). This was expected in view of the experimental results, since the spectral changes induced by aggregation were only observable under laser pumping of the gain media (Figures 6) or by addition of a large amount of water (Figure 7). In addition, the $\theta$ angle increased with respect to the vacuum equilibrium value, although the most probable value was $37^{\circ}$ (Figure 11), which still corresponds to a J-type interaction in terms of Kasha's molecular exciton model (contact angle lower than $\left.54.7^{\circ}\right){ }^{[32]}$

Therefore, the atomistic simulations predicted key differences in the aggregation behavior depending on the methylation of the chromophore and assigned a J-type interaction to dye $\mathbf{1 b}$, which showed the dual emission, as well as an aggregation lifetime in solution longer than the emission one, supporting the hypothesis of laser-induced Jaggregation as the source of the red-shifted laser emission.

\section{Conclusions}

We have developed a facile and very efficient synthesis of a new type of $O$-BODIPY dyes with a spiranic $B$-diacyloxyl structure by reaction of $F$-BODIPYs with dicarboxylic acids promoted by trimethylsilyl chloride under microwave irradiation. The new procedure proved also very efficient for the introduction of monocarboxylic acids and hydroxyacids. 
The combined effect of the diacyloxyl-substitution on boron and the high conformational rigidity of the $B$-spiranic molecular design significantly improved fluorescence quantum yield, photochemical stability, and laser efficiency of the new dyes. Moreover, the orthogonal disposition of the $B$-diacyloxyl substituent and the meso-aryl group with respect to the mean plane of the boradiazaindacene framework, as confirmed by X-ray crystallography, was expected to efficiently hamper intermolecular $\pi$-stacking of the chromophores thus avoiding formation of $\mathrm{H}$-dimers in solution that strongly quench fluorescence. This allowed us to observe for the first time highly efficient and stable redshifted laser emission from J-aggregates in pure organic solvents for some of the new dyes. Key to the effectiveness of this process is the molecular design of new dyes, the high intensity and coherence of the pump laser radiation as well as the feedback provided by the resonant cavity. The role of J-aggregates to explain the dual laser emission observed has been supported by spectroscopic measurements in water-rich mixtures and atomistic simulations, both in vacuum and in a solvent cage. The dynamic calculations predicted key differences in the aggregation behavior of the new dyes depending on the alkylation pattern of the BODIPY chromophore and supported the involvement of J-type aggregates as the source of the red-shifted laser emission in the case of dye $\mathbf{1 b}$ with a 1,3,5,7-tetramethylboradiazaindazene system and its absence for $\mathbf{2} \mathbf{b}$ that has a non-alkylated chromophore.

Acknowledgements. We gratefully acknowledge financial support by the Spanish Ministerio de Economia y Competitividad (projects MAT2014-51937-C3-1-P, MAT201451937-C3-2-P, MAT2014-51937-C3-3-P, and MAT2015-68837-REDT). I. E. thanks the Gobierno Vasco (IT339-10) for a predoctoral contract. H. M. acknowledges the Spanish 
Ministerio de Economia y Competitividad for a Juan de la Cierva postdoctoral contract. The authors thank SGIker of UPV/EHU for technical and human support with the X-ray diffraction measurements and computational calculations, which were carried out in the "arina" informatic cluster. We also thank Diego Plaza Lozano for preliminary synthetic studies.

\section{Supporting Information}

Supplementary figures and tables, X-ray diffraction structures, experimental procedures, spectroscopic characterization, and copies of the ${ }^{1} \mathrm{H}$ and ${ }^{13} \mathrm{C}$ NMR spectra of the new BODIPY products.

\section{References}

[1] (a) T.E. Kaiser, V. Stepanenko and F. Würthner, J. Am. Chem. Soc. 2009, 131, 6719. (b)

F. Würthner, T.E. Kaiser and C.R. Saha-Möller, Angew. Int. Ed., 2011, 50, 3376. (c) J. Mei, N.L. Leung, R.T.K. Kwok, J.W.Y. Lam and B.Z. Tang, Chem. Rev. 2015, 115 (21), 11718.

[2] (a) T.T. Vu, M. Dvorko, E.Y. Schmidt, J.-F. Audibert, P. Retailleau, B.A. Trofimov, R.B. Pansu, G. Clavier and R. Meallet-Renault, J. Phys. Chem. C, 2013, 117, 5373; (b) S. Choi, J. Bouffard and Y. Kim, Chem. Sci., 2014, 5, 751.

[3] (a) F. Camerel, L. Bonardi, M. Schmutz and R. Ziessel J. Am. Chem. Soc., 2006, 128, 4548; (b) X. Zhang, Z. Chen and F. Würthner, J. Am. Chem. Soc., 2007, 129, 4886; (c) J. H. Olivier, J. Widmaier and R. Ziessel, Chem. Eur. J., 2011, 17, 11709. 
[4] (a) H. Lin, R. Camacho, Y. Tian, T.E. Kaiser, F. Würthner and I. G. Scheblykin, Nano Lett., 2010, 10, 620; (b) F. Fennel, S. Wolter, Z. Xie, P.-A. Plötz, O. Kühn, F. Würthner and S. Lochbrunner, J. Am. Chem. Soc., 2013, 135, 18722. (c) V.Y. Petrenko and O. P. Dimitriev, ChemPhysChem, 2014, 15, 3938.

[5] (a) A. Loudet and K. Burgess, Chem. Rev., 2007, 107, 4891; (b) R. Ziessel, G. Ulrich and A. Harriman, New J. Chem., 2007, 31, 496; (c) F. L. Arbeloa, J. Banuelos, V. Martinez, T. Arbeloa and I. L. Arbeloa, Trends Phys. Chem., 2008, 13, 101; (d) G. Ulrich, R. Ziessel and A. Harriman, Angew. Chem. Int. Ed., 2008, 47, 1184; (e) A. C. Benniston and G. Copley, Phys. Chem. Chem. Phys., 2009, 11, 4124; (f) H. Lu, J. Mack, Y. Yang and Z. Shen, Chem. Soc. Rev., 2014, 43, 4778; (g) V. Lakshmi, M. Rajeswara Rao and M. Ravikanth, Org. Biomol. Chem., 2015, 13, 2501.

[6] (a) J. O. Escobedo, O. Rusin, S. Lim and R. M. Strongin, Curr. Opin. Chem. Biol., 2010, 14, 64; (b) X. Qian, Y. Xiao, Y. Xu, X. Guo, J. Qian and W. Zhu, Chem. Commun., 2010, 46, 6418; (c) N. Boens, V. Leen and W. Dehaen, Chem. Soc. Rev., 2012, 41, 1130; (d) Y. Ni and J. Wu, Org. Biomol. Chem., 2014, 12, 3774; (e) K. Umezawa, D. Citterio and K. Suzuki, Anal. Sci. 2014, 30, 327.

[7] (a) S. H. Lim, C. Thivierge, P. Nowak-Sliwinska, J. Han, H. van den Bergh, G. Wagnieres, K. Burgess and H. B. Lee, J. Med. Chem., 2010, 53, 2865; (b) S. G. Awuah and Y. You, $R S C A d v ., 2012,2,11169 ;$ (c) A. Kamkaew, S. H. Lim, H. B. Lee, L. V. Kiew, L. Y. Chung and K. Burgess, Chem. Soc. Rev., 2013, 42, 77.

[8] (a) F. Lopez Arbeloa, J. Banuelos, V. Martinez, T. Arbeloa and I. Lopez Arbeloa, Int. Rev. Phys. Chem., 2005, 24, 339; (b) O. Garcia, R. Sastre, D. d. Agua, A. Costela and I. Garcia-Moreno, Chem. Mater., 2006, 18, 601; (c) O. Garcia, R. Sastre, D. del Agua, A. 
Costela, I. Garcia-Moreno, F. Lopez Arbeloa, J. Banuelos Prieto and I. Lopez Arbeloa, J. Phys. Chem. C, 2007, 111, 1508; (d) I. Garcia-Moreno, F. Amat-Guerri, M. Liras, A. Costela, L. Infantes, R. Sastre, F. L. Arbeloa, J. B. Prieto and I. L. Arbeloa, Adv. Funct. Mater., 2007, 17, 3088; (e) M. Liras, J. B. Prieto, M. Pintado-Sierra, F. L. Arbeloa, I. Garcia-Moreno, A. Costela, L. Infantes, R. Sastre and F. Amat-Guerri, Org. Lett., 2007, 9, 4183; (f) M. Alvarez, A. Costela, I. Garcia-Moreno, F. Amat-Guerri, M. Liras, R. Sastre, F. Lopez Arbeloa, J. Banuelos Prieto and I. Lopez Arbeloa, Photochem. Photobiol. Sci., 2008, 7, 802; (g) A. Costela, I. Garcia-Moreno, M. Pintado-Sierra, F. Amat-Guerri, M. Liras, R. Sastre, F. L. Arbeloa, J. B. Prieto and I. L. Arbeloa, J. Photochem. Photobiol. A, 2008, 198, 192; (h) O. Garcia, L. Garrido, R. Sastre, A. Costela and I. Garcia-Moreno, Adv. Funct. Mater., 2008, 18, 2017; (i) A. Costela, I. Garcia-Moreno, M. Pintado-Sierra, F. Amat-Guerri, R. Sastre, M. Liras, F. Lopez Arbeloa, J. Banuelos Prieto and I. Lopez Arbeloa, J. Phys. Chem. A, 2009, 113, 8118; (j) I. Garcia-Moreno, D. Zhang, A. Costela, V. Martin, R. Sastre and Y. Xiao, J. Appl. Phys., 2010, 107, 073105; (k) M. J. Ortiz, I. Garcia-Moreno, A. R. Agarrabeitia, G. Duran-Sampedro, A. Costela, R. Sastre, F. Lopez Arbeloa, J. Banuelos Prieto and I. Lopez Arbeloa, Phys. Chem. Chem. Phys., 2010, 12, 7804.

[9] (a) L. Bonardi, H. Kanaan, F. Camerel, P. Jolinat, P. Retailleau and R. Ziessel, Adv. Funct. Mater., 2008, 18, 401; (b) M. Benstead, G. H. Mehl and R. W. Boyle, Tetrahedron, 2011, 67, 3573; (c) S. Xiao, Q. Cao and F. Dan, Curr. Org. Chem., 2012, 16, 2970.

[10] (a) A. Bessette and G. S. Hanan, Chem. Soc. Rev., 2014, 43, 3342; (b) M. E. ElKhouly, S. Fukuzumi and F. D'Souza, ChemPhysChem, 2014, 15, 30; (c) S. P. Singh and T. Gayathri, Eur. J. Org. Chem., 2014, 4689. 
[11] (a) H. L. Kee, C. Kirmaier, L. Yu, P. Thamyongkit, W. J. Youngblood, M. E. Calder, L. Ramos, B. C. Noll, D. F. Bocian, W. R. Scheidt, R. R. Birge, J. S. Lindsey and D. Holten, J. Phys. Chem. B, 2005, 109, 20433; (b) G. Durán-Sampedro, A. R. Agarrabeitia, L. Cerdán, M. E. Pérez-Ojeda, A. Costela, I. García-Moreno, I. Esnal, J. Bañuelos, I. L. Arbeloa and M. J. Ortiz, Adv. Funct. Mater., 2013, 23, 4195; (c) A. L. Nguyen, P. Bobadova-Parvanova, M. Hopfinger, F. R. Fronczek, K. M. Smith and M. G. H. Vicente, Inorg. Chem., 2015, 54, 3228.

[12] (a) L. Yang, R. Simionescu, A. Lough and H. Yan, Dyes Pigm., 2011, 91, 264; (b) X.D. Jiang, J. Zhang, T. Furuyama and W. Zhao, Org. Lett., 2012, 14, 248.

[13] (a) Y. Gabe, T. Ueno, Y. Urano, H. Kojima and T. Nagano, Anal Bioanal Chem, 2006, 386, 621; (b) V. J. Richards, A. L. Gower, J. E. H. B. Smith, E. S. Davies, D. Lahaye, A. G. Slater, W. Lewis, A. J. Blake, N. R. Champness and D. L. Kays, Chem. Commun., 2012, 48, 1751.

[14] (a) B. Brizet, C. Bernhard, Y. Volkova, Y. Rousselin, P. D. Harvey, C. Goze and F. Denat, Org. Biomol. Chem., 2013, 11, 7729; (b) A. Romieu, C. Massif, S. Rihn, G. Ulrich, R. Ziessel and P.-Y. Renard, New J. Chem., 2013, 37, 1016; (c) A. M. Courtis, S. A. Santos, Y. Guan, J. A. Hendricks, B. Ghosh, D. M. Szantai-Kis, S. A. Reis, J. V. Shah and R. Mazitschek, Bioconjugate Chem., 2014, 25, 1043.

[15] (a) Y. Kubota, J. Uehara, K. Funabiki, M. Ebihara and M. Matsui, Tetrahedron Lett., 2010, 51, 6195; (b) Y. Tokoro, A. Nagai and Y. Chujo, Tetrahedron Lett., 2010, 51, 3451.

[16] (a) C. Ikeda and T. Nabeshima, Chem. Commun., 2008, 721; (b) A. Harriman, L. J. Mallon, K. J. Elliot, A. Haefele, G. Ulrich and R. Ziessel, J. Am. Chem. Soc., 2009, 131, 
13375; (c) H. Maeda, Y. Nishimura, S. Hiroto and H. Shinokubo, Dalton Trans., 2013, 42,15885 .

[17] (a) G. Ulrich, C. Goze, M. Guardigli, A. Roda and R. Ziessel, Angew. Chem. Int. Ed., 2005, 44, 3694; (b) B. Brizet, A. Eggenspiller, C. P. Gros, J.-M. Barbe, C. Goze, F. Denat and P. D. Harvey, J. Org. Chem., 2012, 77, 3646; (c) E. M. Sanchez-Carnerero, L. Gartzia-Rivero, F. Moreno, B. L. Maroto, A. R. Agarrabeitia, M. J. Ortiz, J. Banuelos, I. Lopez-Arbeloa and S. de la Moya, Chem. Commun., 2014, 50, 12765; (d) I. Esnal, G. Duran-Sampedro, A. R. Agarrabeitia, J. Banuelos, I. Garcia-Moreno, M. A. Macias, E. Pena-Cabrera, I. Lopez-Arbeloa, S. de la Moya and M. J. Ortiz, Phys. Chem. Chem. Phys., 2015, 17, 8239; (e) M. Yamamura, S. Yazaki, M. Seki, Y. Matsui, H. Ikeda and T. Nabeshima, Org. Biomol. Chem., 2015, 13, 2574.

[18] E. M. Sánchez-Carnerero, F. Moreno, B. L. Maroto, A. R. Agarrabeitia, M. J. Ortiz, B. G. Vo, G. Muller and S. d. 1. Moya, J. Am. Chem. Soc., 2014, 136, 3346.

[19] (a) D. A. Smithen, A. E. G. Baker, M. Offman, S. M. Crawford, T. S. Cameron and A. Thompson, J. Org. Chem., 2012, 77, 3439; (b) T. Lundrigan, S. M. Crawford, T. S. Cameron and A. Thompson, Chem. Commun., 2012, 48, 1003; (c) T. Lundrigan and A. Thompson, J. Org. Chem., 2013, 78, 757; (d) T. Lundrigan, T. S. Cameron and A. Thompson, Chem. Commun., 2014, 50, 7028.

[20] H. Kim, A. Burghart, M. B. Welch, J. Reibenspies and K. Burgess, Chem. Commun., 1999, 1889.

[21] C. Tahtaoui, C. Thomas, F. Rohmer, P. Klotz, G. Duportail, Y. Mély, D. Bonnet and M. Hibert, J. Org. Chem., 2007, 72, 269.

[22] J. A. Hendricks, E. J. Keliher, D. Wan, S. A. Hilderbrand, R. Weissleder and R. Mazitschek, Angew. Chem. Int. Ed., 2012, 51, 4603. 
[23] (a) S. Shaban Ragab, S. Swaminathan, E. Deniz, B. Captain and F. M. Raymo, Org. Lett., 2013, 15, 3154; (b) N. Umeda, H. Takahashi, M. Kamiya, T. Ueno, T. Komatsu, T. Terai, K. Hanaoka, T. Nagano and Y. Urano, ACS Chem. Biol., 2014, 9, 2242.

[24] A. B. Nepomnyashchii, M. Broering, J. Ahrens and A. J. Bard, J. Am. Chem. Soc., $2011, \mathbf{1 3 3}, 8633$.

[25] (a) M. Shah, K. Thangaraj, M. L. Soong, L. Wolford, J. H. Boyer, I. R. Politzer and T. G. Pavlopoulos, Heteroat. Chem., 1990, 1, 389; (b) B. Guo, X. Peng, A. Cui, Y. Wu, M. Tian, L. Zhang, X. Chen and Y. Gao, Dyes Pigments, 2006, 73, 206; (c) A. C. Benniston, G. Copley, K. J. Elliott, R. W. Harrington and W. Clegg, Eur. J. Org. Chem., 2008, 2705. [26] L. Xu, Y. Li, R. Jiang, Z. Qin and Y. Li, Dyes Pigments, 2014, 107, 90.

[27] (a) W. L. Sha, C.-H. Liu, F. Feng Liu and R. R. Alfano, Opt. Lett., 1996, 21, 1277; (b) R. M. Balachandran, N. M. Lawandy, Opt. Lett., 1996, 21, 1603; (c) R. M. Masilamani and N. M. Aldwayyan, Spectrochimica Acta Part A, 2004, 60, 2099; (d) M. Alvarez, A. Costela, I. Garcia-Moreno, F. Amat-Guerri, M. Liras, R. Sastre, F. Lopez Arbeloa, J. Bañuelos Prieto and I. Lopez Arbeloa, J. Appl. Phys., 2007, 101 113110; (e) C. T. Dominguez, E. Lima, P. C. Oliveira and F. Lopez Arbeloa, Chem. Phys. Lett., 2008, 464, 245; $(f)$ L. Cerdán, A. Costela, G. Duran-Sampedro and I. Garcia-Moreno, Appl. Phys. B, 2012, 108, 839; (g) L. Cerdán, V. Martinez, I. García-Moreno, A. Costela, M. E. Perez-Ojeda, I. Lopez Arbeloa, L. Wu and K. Burgess, Adv. Optical Mater., 2013, 1, 984.

[28] (a) S. Ozcelik, I. Ozcelik and D. L. Akins, Appl. Phys. Lett., 1998, 73, 1949; (b) M. S. Bradley, J. R. Tischler and V. Bulovix, Adv. Mater., 2005, 17, 1881; (c) D. H. Arias, K.W. Stone, S. M. Vlaming, B. J. Walker, M. G. Bawendi, R. J. Silbey, V. Bulovic and K. A. Nelson, J. Phys. Chem. B, 2013, 117, 4553; (d) K. D. B. Higgins, S. C. Benjamin, 
T. M. Stace, G. J. Milburn, B.W. Lovett and E. M. Gauger, Nat. Commun., 2014, 5, 5705.

[29] S. K. Saikin, A. Eisfeld, S. Valleau and A. Aspuru-Guzik, Nanophotonics, 2013, 2, 21. [30] I. López Arbeloa, J. Photochem., 1980, 14, 97.

[31] R. Hu, E. Lager, A. Aguilar-Aguilar, J. Liu, J. W. Y. Lam, H. H. Y. Sung, I. D. Williams, Y. hong, K. S. Wong, E. Peña-Cabrera and B. Z. Tang, J. Phys. Chem. C., 2009, 113, 15845.

[32] M. Kasha, Radiat. Res., 1963, 20, 55. 


\section{ToC abstract}

$O$-BODIPYs with a $B$-spiranic 4,4-diacyloxyl substitution pattern enable the spontaneous formation of stable J-aggregates in pure organic solvents like ethanol or ethyl acetate. The photophysical and laser properties of the new dyes as well as atomistic simulations both in vacuum and in solvent cage provide convincing evidence for the unambiguous assignment of these J-aggregates and their dependence on the environmental conditions.

\section{Photoluminescence}

Hegoi Manzano, Ixone Esnal, Tamara Marques-Matesanz, Jorge Bañuelos, Iñigo LópezArbeloa, María J. Ortiz, Luis Cerdán, *Angel Costela, Inmaculada García-Moreno, Jose Luis Chiara*

\section{Unprecedented J-Aggregated Dyes in Pure Organic Solvents}

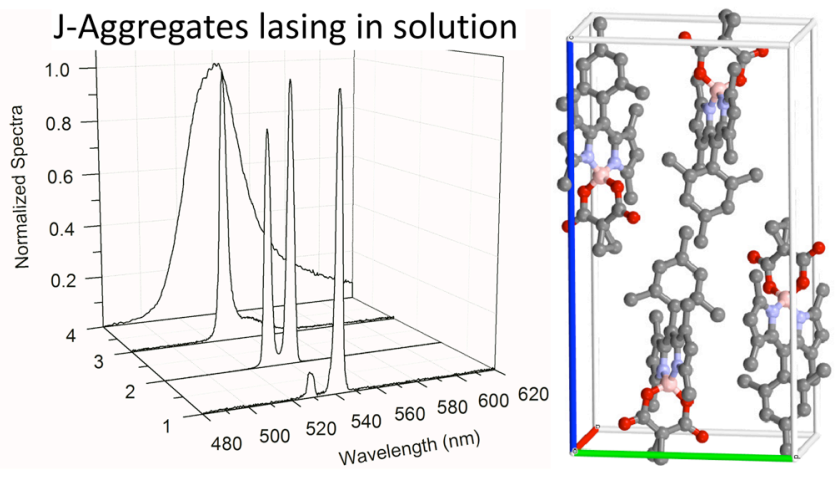

